\title{
The relationship between activity clusters detected by an automatic activity monitor and endocrine changes during the periestrous period in lactating dairy cows
}

\author{
S. P. M. Aungier, ${ }^{*}$ J. F. Roche, ${ }^{*}$ P. Duffy, $†$ S. Scully, ${ }^{*}$ and M. A. Crowe ${ }^{*}{ }^{1}$ \\ *School of Veterinary Medicine, University College Dublin, Belfield, Dublin 4, Ireland \\ †Lyons Research Farm, University College Dublin, Newcastle, Co. Dublin, Ireland \\ ¥Conway Institute for Biomolecular and Biomedical Research, University College Dublin, Belfield, Dublin 4, Ireland
}

\begin{abstract}
The aim of this study was to determine the relationship between observed estrous-related behavior, activity clusters (AC; detected by automatic activity monitor), endocrine profiles, and ovulation time. Twenty-one cows in estrus (after 2 cloprostenol treatments, $11 \mathrm{~d}$ apart) and 12 nonsynchronized cows, to establish Heatime (SCR Engineers Ltd., Netanya, Israel) herd baseline activity, were enrolled. Cows had Heatime monitors applied 3 wk before the trial to establish their own baseline activity level. Cows in standing estrus had ultrasonography and phlebotomy carried out every $4 \mathrm{~h}$ to determine dominant follicle size, endocrine profiles, and ovulation time. After ovulation, these procedures were repeated once on $\mathrm{d} 3$ to 6 . Heatime alerted estrus in $90 \%$ of cows, and incorrectly alerted $17 \%$ of AC. The mean \pm SEM duration for standing estrus was 9 \pm 1 and $13 \pm 1 \mathrm{~h}$ for estrous-related behavior. Estrousrelated behavior began after the start of the proestrous estradiol-17 $\beta\left(\mathrm{E}_{2}\right)$ increase $(59 \pm 6.5 \mathrm{~h})$. Cows with longer durations of raised proestrous $\mathrm{E}_{2}$ had longer intervals from its onset to the start of standing estrus and AC. The AC duration increased with longer durations of estrous-related behavior. Higher peak $\mathrm{E}_{2}$ occurred with longer standing estrus and estrous-related behavior. As $\mathrm{E}_{2}$ concentration decreased after the peak, $90 \%$ of cows still had estrous-related behavior. Duration of estrous-related behavior increased with higher average $\mathrm{E}_{2}$ concentration during the last $8 \mathrm{~h}$ before the start of the LH surge. During this surge $90 \%$ of cows had all of their standing estrus. As yields increased, so did the magnitude of the preovulatory FSH surges. Higher surges occurred with shorter standing estrus and estrous-related behavior. Cows with shorter LH surges had longer standing estrus. Peak LH preceded the AC peak $(6.6 \pm 0.8 \mathrm{~h})$. Duration of overlap between the AC
\end{abstract}

Received August 22, 2013.

Accepted October 25, 2014.

${ }^{1}$ Corresponding author: mark.crowe@ucd.ie start and the LH surge end ranged between 0 and $14 \mathrm{~h}$; 1 cow had none. No association was found between the $\mathrm{AC}$ characteristics with the $\mathrm{E}_{2}, \mathrm{LH}$, or FSH profiles. In conclusion, the relationship between the timing of the $\mathrm{E}_{2}$ increase and estrous activity may be mediated by other factors (GnRH surge). Estrous-related behavior, but not endocrine profiles, was related to $\mathrm{AC}$ duration. Timing of standing estrus during the LH surge ensures that mating allows sperm maturation before ovulation. Based on the interval from the start of an $\mathrm{AC}$ to ovulation $(27 \pm 1 \mathrm{~h})$, the optimum time to artificial insemination is, on average, between 9 and $15 \mathrm{~h}$ after the AC start.

Key words: dairy cow, automatic activity monitor, endocrine profile, estrous behavior

\section{INTRODUCTION}

Artificial insemination using semen from high-genetic merit sires results in increased genetic merit of the offspring. The main problems associated with its use are the accurate identification of cows in estrus and deciding the optimum time to inseminate cows detected in estrus. Monitoring of estrous behavior in cows is very labor intensive, and accuracy is affected by the fact that modern, high-yielding Holstein dairy cows ( 10,000 L; quoted by Dobson et al., 2007) are only in estrus for a short period of time. One trial, monitoring 17 farms using HeatWatch (DDx Inc., Denver, CO) to detect estrous activity, found that the number of standing events during estrus averaged $( \pm \mathrm{SD}) 8.5 \pm 6.6$ per cow, and the average duration of estrus was $7.1 \pm 5.4 \mathrm{~h}$ (Dransfield et al., 1998). Lopez et al. (2004) identified that, in the $10 \mathrm{~d}$ preceding estrus, high-producing cows $(\geq 39.5 \mathrm{~kg} / \mathrm{d})$ had larger follicles but lower circulating estradiol-17 $\beta\left(\mathbf{E}_{2}\right)$ compared with lower-producing cows $(<39.5 \mathrm{~kg} / \mathrm{d})$. Higher-yielding dairy cows $(\geq 39.5 \mathrm{~kg} / \mathrm{d})$ had shorter durations of standing to be mounted (6.2 \pm 0.5 compared with $10.9 \pm 0.7 \mathrm{~h} ; P<0.0001$ ), decreased number of standing events $(6.3 \pm 0.4$ compared with $8.8 \pm 0.6 ; P=0.001)$, and reduced duration of stand- 
ing time $(21.7 \pm 1.3$ compared with $28.2 \pm 1.9 \mathrm{~s} ; P=$ $0.007)$ when compared with lower-yielding cows $(<39.5$ $\mathrm{kg} / \mathrm{d}$ ).

It has been suggested that the reduced intensity of expression of estrous behavior by high-yielding dairy cows (Lopez et al., 2004) compared with nulliparous heifers (Nebel et al., 1997) may be related to increased metabolism of $\mathrm{E}_{2}$ by the liver due to a higher metabolic rate in Holstein cows (Sangsritavong et al., 2002). Yet other studies have found no correlation between milk yield and estrous expression (Lyimo et al., 2000; Van Eerdenburg et al., 2002). This apparent disagreement in findings may be due to differences in levels of milk production at the time of the different studies and the less frequent periods of visual observation carried out (Lopez et al., 2004).

Other factors have also been identified as affecting the intensity of estrous expression. Negative energy balance during the early postpartum period was shown to affect negatively the development of the preovulatory follicle and estradiol production. Some studies found that the maximum estradiol produced was related to total estrous expression (Lyimo et al., 2000; Roelofs et al., 2004), whereas others disagreed with this finding (Walker et al., 2010). No correlation has been found between follicle size and the intensity of estrous expression (Van Eerdenburg et al., 2002). The genetic background of cows has also been found to influence estrous detection, with the daughters of different sires displaying significantly different estrous behavior intensities (Heres et al., 2000). In nonlame cows, as the size of sexually active groups increase, the intensity of estrous behavior has been found to increase (Hurnik et al., 1975; Roelofs et al., 2005a; Gilmore et al., 2011). Cows that are clinically lame have been shown to express estrus of lower intensity (Walker et al., 2010). In these cows, it was found that although estradiol concentrations were normal, the progesterone $\left(\mathbf{P}_{4}\right)$ concentrations before estrus were not. In ruminants, prior exposure to $\mathrm{P}_{4}$ was previously shown to affect the intensity of estrous behavior (Fabre-Nys and Martin, 1991). Other stressors, such as clinical disease, poor management, and production diseases, also influence the intensity of estrous behavior (Dobson et al., 2008).

Furthermore, in high-yielding dairy cows, the percentage of cows that display standing to be mounted by other cows has decreased, leaving it more difficult to detect estrus. Roelofs et al. (2005a) found that only $58 \%$ of cows were observed in standing estrus. This, in turn, decreases submission rate to AI and thereby contributes significantly to reduced reproductive efficiency (Diskin, 2008). Several aids exist to improve the efficiency of detection of estrus. One such labor-saving technology available to the farmer to help increase submission rate and decrease labor requirements for estrous detection is the use of automated systems.

Attempts have been made to monitor changes in physical activity to predict estrus using these automated systems. The pedometer, attached to a leg, detects an increase in the number of steps taken per hour during estrus (e.g., S.A.E. Afikim, Kibbutz Afikim, Israel; Holman et al., 2011), whereas the use of a neck collar (e.g., Alpro; DeLaval International AB, Tumba, Sweden; Peralta et al., 2005) identifies increased physical activity (walking, mounting, getting up and lying down) expressed as an activity cluster (AC). The characteristic estrous behavior of standing to be mounted can be monitored through the use of systems such as the electronic device HeatWatch, scratch cards (e.g., Estrotect; Rockway Inc., Spring Valley, WI), color ampoules (Kamar Products Inc., Zionsville, IN), vasectomized bulls fitted with a chin-ball marker, or the use of tailpainting methods (Diskin and Sreenan, 2000). A recent study, using the neck collar activity monitor Heatime (SCR Engineers Ltd., Netanya, Israel), identified that the odds of an AC being in a preovulatory follicular phase rather than a luteal phase improved by $29 \%$ for every 1-unit increase in peak activity and by $91 \%$ for every 2-h increase in duration of an AC (Aungier et al., 2012).

To date, the emphasis has been mainly on the study of the efficacy of these aids as physical activity monitors for estrus detection and prediction of the time of ovulation (Roelofs et al., 2005b). However, a lack of data exists on how accurate automatic activity monitors are at identifying the association between the intensity of physical activity associated with estrous behavior and the pattern of endocrine changes during the periovulatory period. There is also a need to revisit the relationship between the pattern of endocrine profiles, observed estrous behavior, and timing of ovulation in modern dairy cows (Roelofs et al., 2005a).

The generally accepted optimum time for insemination of dairy cows is 12 to $18 \mathrm{~h}$ before ovulation (Hunter, 1994). In practical terms, the timing of insemination is usually based on the a.m.-p.m. rule, where a cow observed in standing estrus in the morning is inseminated that afternoon or if identified in the afternoon it is carried out the following morning (Trimberger and Davis, 1943; Trimberger, 1948). The inaccurate timing of insemination in relation to ovulation decreases the conception rate partially due to a decrease in the percentage of viable embryos produced (Roelofs et al., 2006; Dalton, 2011). The relationship between the characteristics of accelerometer AC and time of ovulation require further research. The aims of the current paper were to determine the relationships between (1) observed estrous behavior and the characteristics 
of AC; (2) the characteristics of the endocrine profiles in the preovulatory phase of the estrous cycle and the characteristics of $\mathrm{AC}$ associated with estrous behavior; and (3) the time of ovulation and the Heatime AC characteristics detected.

\section{MATERIALS AND METHODS}

\section{Study Animals}

The study was conducted in 2 replicates (replicate 1 in April and replicate 2 in November, 2011) at the research farm of University College Dublin. A total of 25 cows from the spring-calving cohort and 26 cows from the autumn-calving cohort of a herd of 91 pedigree Holstein-Friesians were selected on the basis that they were at least $30 \mathrm{~d}$ calved. Six nonsynchronized cows in each replicate were chosen at random solely for the purpose of allowing the Heatime activity monitor establish a herd-average baseline activity level. All cows, including the nonsynchronized cows, had Heatime neck activity monitors applied 3 wk before the start of the trial to establish their own baseline activity level. During the trial period, each group of cows was housed in a freestall building with slatted passageways. All cows in replicate 1 were fed freshly cut grass $(13 \mathrm{~kg} / \mathrm{d})$ and were offered $6 \mathrm{~kg}$ of a concentrate ration daily, whereas cows in replicate 2 were fed a grass and maize silage mix $(13 \mathrm{~kg})$ and $6 \mathrm{~kg}$ of a concentrate ration daily. The mean $( \pm$ SEM $) 305$-d lactation milk yield for all cows that participated in the trial (i.e., observed in standing estrus; $\mathrm{n}=21$ cows) was $7,689 \pm 276 \mathrm{~kg}$ (range: 5,370-9,793 kg). The study was approved by the Animal Research Ethics Committee of University College Dublin and was licensed by the Department of Health and Children, Ireland, in accordance with the Cruelty to Animals Act (Ireland, 1876) and the European Union Directive 86/609/EC.

\section{Monitoring of Herd Health}

An individual herd health profile, based on serology, confirmed that all cows were negative for infectious bovine rhinotracheitis, Salmonella Dublin, Salmonella Typhimurium, bovine viral diarrhea, and Johne's disease. The cows in the herd received a vaccination against Leptospira borgpetersenii Hardjo and Leptospira interrogans Hardjo annually.

\section{Reproductive Parameters Monitored}

Cows identified with a corpus luteum (CL) on ultrasonography were synchronized with 2 cloprostenol (Estrumate $500 \mu \mathrm{g}$ im; MSD Ireland Ltd., Dublin, Ire- land) treatments, $11 \mathrm{~d}$ apart. On the day of the second cloprostenol treatment, all cows in each replicate had (1) BCS (Edmonson et al., 1989) and lameness score (Sprecher et al., 1997) assessed and (2) an ultrasound scan (scan) of the reproductive tract to ensure that uterine involution had occurred and that a CL was present. Visual observation for signs of estrous behavior started $24 \mathrm{~h}$ after the cows received the second cloprostenol treatment and was carried out at 8-h intervals on the first day and every $4 \mathrm{~h}$ thereafter for $30 \mathrm{~min}$ until standing estrus was detected. Cows that showed standing estrus within $120 \mathrm{~h}$ of the second cloprostenol treatment continued in the study. Only 10 of 19 cows from replicate 1 (median lactation number $=3$ with lactation number ranging from 1 to 6 ) and only 11 of 20 from replicate 2 were observed in standing estrus (median lactation number $=2$ with lactation number ranging from 1 to 5 ).

Transrectal ultrasonography (scan) of the reproductive tract, using a Voluson i scanner (GE Healthcare, Munich, Germany) fitted with a $12-\mathrm{MHz}$ linear probe operating at a depth of $3.5 \mathrm{~cm}$, was carried out every $4 \mathrm{~h}$ from $12 \mathrm{~h}$ after the onset of standing estrus (at the same time as a blood sample was being collected). At each scan, the diameter of the preovulatory follicle was assessed until ovulation was detected or until the 4-h scan after which it had occurred. If ultrasonography did not occur at the exact time of ovulation, ovulation was estimated to have occurred midway between the scan before and the scan after ovulation. In the case of 3 cows, the dominant follicle was visualized to be undergoing ovulation at the time of scanning. In these instances, the distinct spherical structure of the follicle was not detectable, but follicular fluid was still present. In 2 cows, (cow numbers 803 and 808) after identification of the dominant follicle, ovarian ultrasonography sessions were not again recorded until after ovulation had occurred. Subsequent scans were again carried out on all cows on d $3,4,5$, and 6 after ovulation to confirm the presence of a CL.

\section{Endocrine Profiles During the Periestrous Period}

Blood samples were collected beginning $24 \mathrm{~h}$ after the second cloprostenol treatment. On d 1, a blood sample was collected at 8-h intervals on 3 occasions and, subsequently, they were collected at 4-h intervals until $8 \mathrm{~h}$ after ovulation (confirmed by ultrasonography of the ovaries). A morning blood sample (on d 3, 4, 5 , and 6 postovulation) was collected to monitor $\mathrm{P}_{4}$ concentrations. Blood samples were initially allowed to clot at ambient temperatures for $1 \mathrm{~h}$, and then stored at $4^{\circ} \mathrm{C}$ for 18 to $24 \mathrm{~h}$ followed by centrifuging at 2,000 $\times g$ for $20 \mathrm{~min}$ at $4^{\circ} \mathrm{C}$. The serum supernatant was 
Table 1. Limits of detection, precision, and quality control data for the hormone immunoassays included in this study ${ }^{1}$

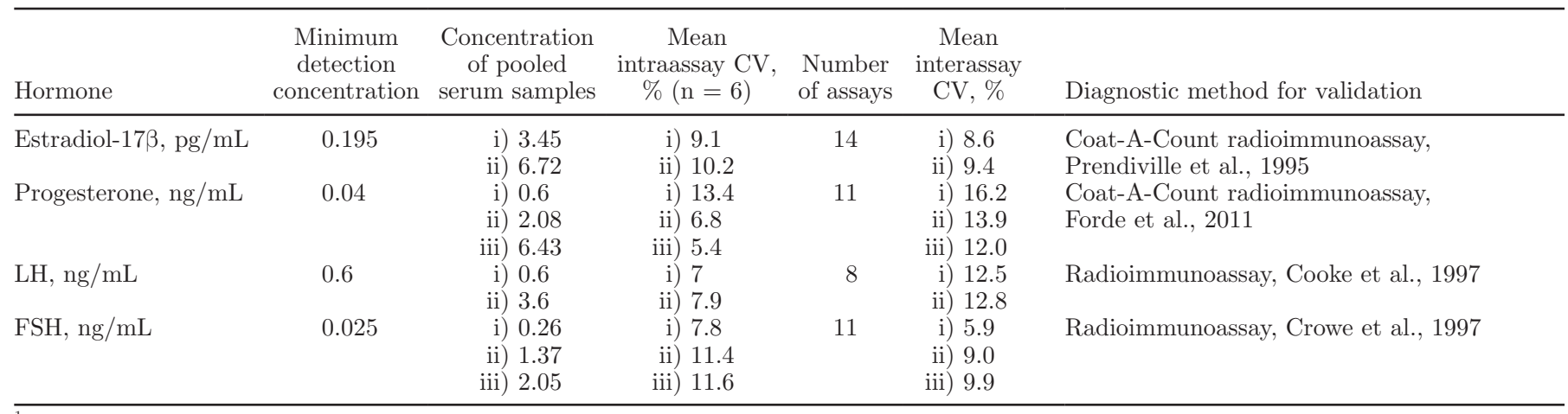

${ }^{1} \mathrm{i}$, ii, and iii represent the quality-control sera pools used in each assay.

decanted into tubes and stored at $-20^{\circ} \mathrm{C}$ until assayed. Previously validated radioimmunoassays were used to quantify serum concentrations of $\mathrm{E}_{2}$ (Prendiville et al., 1995), $\mathrm{P}_{4}$ (Forde et al., 2011), LH (Cooke et al., 1997), and FSH (Crowe et al., 1997). Limits of detection, precision, and quality control data for the hormone immunoassays included in the study are presented in Table 1.

The endocrine profiles were characterized as follows during the periestrous period.

(1) A proestrous increase in serum $\mathrm{E}_{2}$ : the magnitude of the proestrous increase was defined as the area under the curve (AUC). It was calculated from the first blood sample above the threshold to the last sample above the threshold after the peak of the $\mathrm{E}_{2}$ increase. The threshold was defined as the baseline $+2 \mathrm{SD}$. The baseline was the average of 4 consecutive, $4-\mathrm{h} \mathrm{E}_{2}$ serum concentrations starting with the time of the scan that confirmed that ovulation had occurred. The SD were calculated during this baseline period.

(2) A proestrous surge in serum LH: this was defined as an increase in the concentration of $\mathrm{LH}$ above the mean of the presurge baseline LH concentrations plus $2 \mathrm{SD}$; it was calculated as the AUC.

(3) A coincident serum preovulatory FSH surge with the LH surge: the FSH surge was defined as an increase in the concentration of FSH above the mean of the presurge baseline FSH concentrations plus 2 SD until the FSH decreased to the nadir value between this preovulatory increase and the periovulatory increase; it was calculated as the AUC.

(4) A parallel decline in serum $\mathrm{LH}$ and serum $\mathrm{E}_{2}$ concentrations.

(5) A periovulatory increase in serum FSH which was the first transient increase in FSH concentration associated with the emergence of the next follicular wave. The AUC was calculated for the periovulatory increase from the nadir value between the end of the preovulatory surge and the start of the periovulatory increase to a return to the subsequent nadir value of FSH at the end of the periovulatory increase.

The AUC for each hormone was calculated using the trapezoidal rule (Friend et al., 1977).

\section{Heatime AC}

Heatime records the activity of 2-h blocks. When the average SD of the previous 4 consecutive 2 -h blocks was $\geq 5 \mathrm{SD}$ above the average movement of the cow over the corresponding period for the previous week, Heatime would alert that an $\mathrm{AC}$ was ongoing. Heatime $\mathrm{AC}$ were defined as correct when they were accompanied by behavioral estrus and subsequent ovulation. An AC was defined as a false positive when it was not accompanied by detection of behavioral estrus nor ovulation. An AC was defined as missed when behavioral estrus, followed by ovulation, was not accompanied by an AC. Behavioral estrus included 2 aspects of estrous behavior. It was defined as either (1) estrous-related behavior, which described the total amount of time mounting other cows and standing to be mounted for cows that went on to ovulate, or (2) standing estrus, which was the total period that a cow stood to be mounted during estrus.

\section{Statistical Analyses}

All analyses were performed using the SAS 9.1 software package (SAS Institute, Inc., Cary, NC). Data on the relationships between endocrine profiles, Heatime $\mathrm{AC}$ characteristics, observed estrus, and the timing of ovulation were analyzed using general linear regression (Proc GLM). In all cases where equations were derived from linear regression analysis, they are presented in 
Supplemental Table S1 (http://dx.doi.org/10.3168/ jds.2013-7405). The data collected from both replicates were amalgamated for analysis because they were not affected by replicate. Cow was the experimental unit used throughout the analysis. The data were checked for normality and homogeneity by histograms, qqplots, and formal statistical tests using the Univariate procedure in SAS. Data that were not normally distributed were transformed by having the response variable modeled as log-normal. The transformed value was used to calculate the $P$-value.

\section{RESULTS}

\section{$A C$ and Observed Estrous Behavior}

The sequence of occurrence of the interval from the start of an AC to estrous-related behavior was similar for all cows in the trial (Figure 1). Of the 21 cows that displayed behavioral estrus and subsequently ovulated, 2 cows did not have an $\mathrm{AC}$ using $\geq 5 \mathrm{SD}$ for the peak activity threshold; peak activities recorded were 3.8 and 4 SD for cow numbers 727 and 728 , respectively. Cow number 727 had a false-positive AC, which occurred before the start of the preovulatory LH surge. Standing estrus was displayed for 4 (cow number 727) and $12 \mathrm{~h}$ (cow number 728), and estrous-related behavior was displayed for 8 (1 visual observation period with mounting occurring followed by 1 period of standing to be mounted) and $12 \mathrm{~h}$ ( 3 consecutive visual observation periods when standing to be mounted was observed), respectively. The established 5-SD peak activity threshold resulted in a total of 4 false positive AC. Of the 19 cows that had an AC at the correct time, $79 \%(15 / 19)$ of cows were confirmed to be in standing estrus, whereas a further 3 cows displayed physical mounting behavior only and 1 cow did not display any observed estrous-related behavior before the start of an AC. Details for 17 cows, which had both an AC and an identified time of ovulation, are presented (Figure 1$)$. The mean $( \pm$ SEM) duration of estrous-related behavior $(13 \pm 1 \mathrm{~h})$ was on average $2 \mathrm{~h}$ longer than the average duration of an $\mathrm{AC}$ $(11 \pm 1 \mathrm{~h}$; paired $t$-test $=2.05 ; P=0.06)$. The mean duration of standing estrus $(9 \pm 1 \mathrm{~h})$ was on average 2 $\mathrm{h}$ shorter than the average duration of an AC (paired $t$-test $=1.2 ; P=0.25)$. The duration of an $\mathrm{AC}$ was longer when the duration of estrous-related behavior was longer (F-statistic $=3.23 ; P=0.09 ; \mathrm{R}^{2}=0.16$ ). No change was found in the duration of an $\mathrm{AC}$ with a change in duration of standing estrus (F-statistic $=$ $\left.0.14 ; P=0.7 ; \mathrm{R}^{2}=0.01\right)$. No change in the peak intensity of an $\mathrm{AC}$ was observed with a change in either the duration of estrous-related behavior $(\mathrm{F}$-statistic $=0.6$;
$\left.P=0.4 ; \mathrm{R}^{2}=0.03\right)$ or the duration of standing estrus $\left(\right.$ F-statistic $\left.=0.51 ; P=0.5 ; \mathrm{R}^{2}=0.03\right)$.

\section{Relationship Between Endocrine Profiles, Observed Estrous Behavior, and Interval to Ovulation}

The mean interval from the start of the $\mathrm{E}_{2}$ (above threshold) increase to the occurrence of endocrine events and observed estrous-related behavior ( $\mathrm{n}=21$ cows) are presented in Figure 2. All 21 cows had a preovulatory $\mathrm{E}_{2}$ increase, a parallel $\mathrm{LH}$ and $\mathrm{E}_{2}$ decline, and a periovulatory FSH increase. A coincident LH surge and preovulatory FSH surge occurred in 20 of the 21 cows. The magnitude (AUC) of the LH surge increased as the magnitude of the preovulatory FSH surge increased (Fstatistic $\left.=9.29 ; P=0.007 ; \mathrm{R}^{2}=0.34\right)$. The magnitude of the preovulatory FSH surge was greater in cows with higher 305-d milk yields $(\mathrm{F}$-statistic $=5.91 ; P=0.03$; $\left.\mathrm{R}^{2}=0.25\right)$ but was not related to the magnitude of the $\mathrm{E}_{2}$ increase (F-statistic $=1.82 ; P=0.2 ; \mathrm{R}^{2}=0.09$ ). The magnitude of the LH surge did not change with a change in the (1) AUC of the $\mathrm{E}_{2}$ increase (F-statistic $\left.=2.29 ; P=0.15 ; \mathrm{R}^{2}=0.11\right),(2)$ the duration of the $\mathrm{E}_{2}$ increase above the threshold (F-statistic $=0.22 ; P$ $\left.=0.65 ; \mathrm{R}^{2}=0.01\right)$, (3) the mean $\mathrm{E}_{2}$ concentration of the last $8 \mathrm{~h}$ (last 2 serum samples) before the start of the LH surge (F-statistic $\left.=0.53 ; P=0.5 ; \mathrm{R}^{2}=0.03\right)$, or (4) the peak $\mathrm{E}_{2}$ concentration of the $\mathrm{E}_{2}$ increase (Fstatistic $\left.=0.3 ; P=0.6 ; \mathrm{R}^{2}=0.02\right)$. Nineteen cows had an LH surge with peak serum concentrations of LH ranging from 5.2 to $23.9 \mathrm{ng} / \mathrm{mL}$. The other 2 cows had a recorded peak LH of 2 (cow 754) and $4 \mathrm{ng} / \mathrm{mL}$ (cow 790), respectively. The mean \pm SEM pre-ovulatory LH surge AUC was $52 \pm 6(21-127)$ and the preovulatory FSH surge AUC was $4.3 \pm 0.3$ (range 2-6).

The start of estrous-related behavior lagged behind the start of the period when an increase in proestrous $\mathrm{E}_{2}$ concentration (above threshold) was observed (Figure 2). The mean interval between the start of the $E_{2}$ increase above threshold and the start of estrous-related behavior was $59 \pm 6.5 \mathrm{~h}$ (range $24-132 \mathrm{~h}$; $\mathrm{n}=21$ cows). In 19 cows, estrous-related behavior was still being observed after the proestrous increase in $\mathrm{E}_{2}$ started to decline; for 14 of these cows, standing estrus was the last activity recorded. For the remaining 2 cows, (cow numbers 803 and 808) a standing estrus was the last activity recorded, and this occurred at the time of the peak in the $\mathrm{E}_{2}$ increase. Fifteen hours before the start of standing estrus, $\mathrm{E}_{2}$ concentrations were, on average, $>80 \%$ of their peak concentrations. The interval from the start of standing estrous behavior to ovulation (estimated by ultrasonography) was evaluated for 19 cows. The remaining 2 cows (cow numbers 451 and 


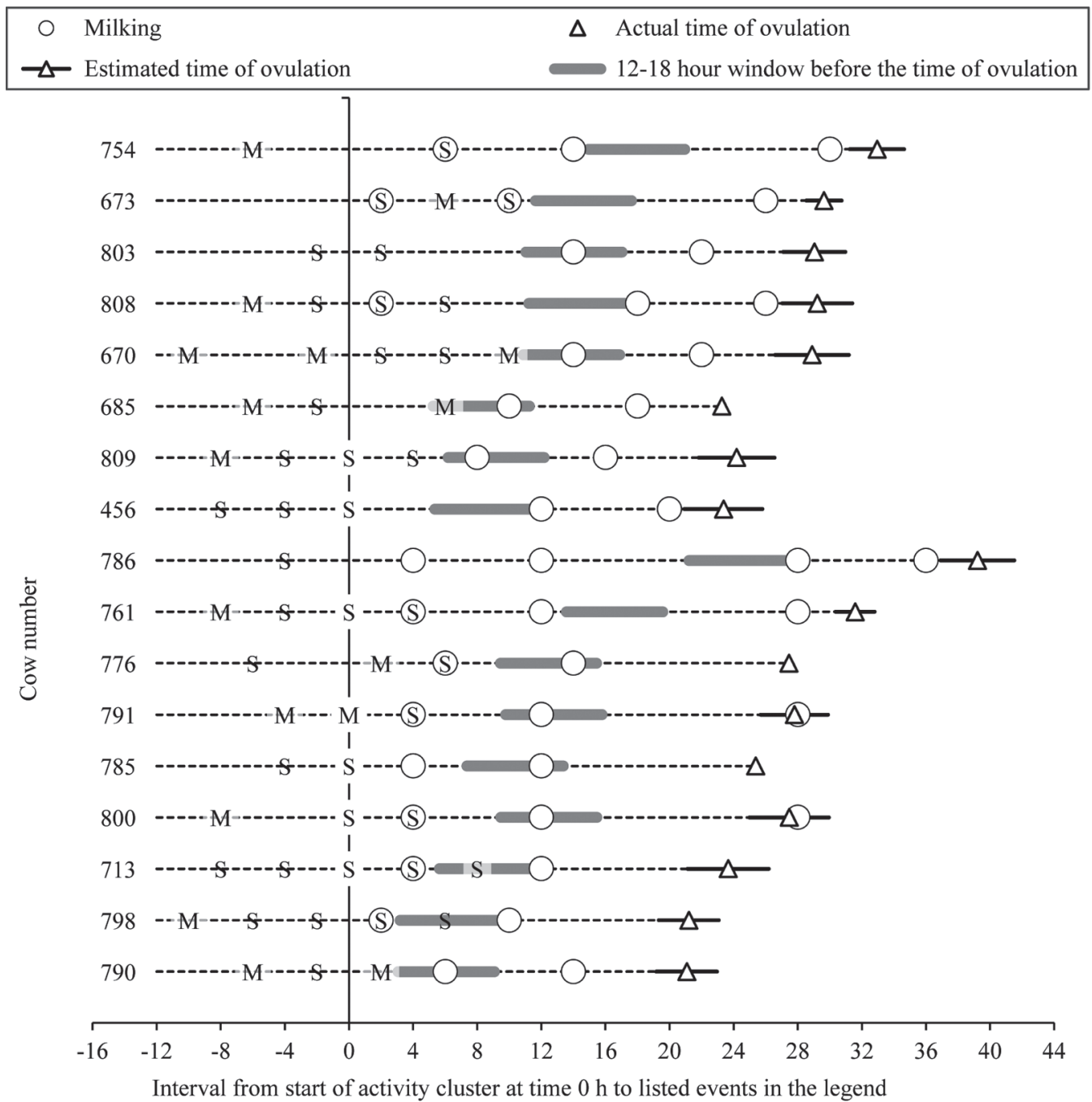

Figure 1. The interval from the start of the activity clusters (AC) to the actual or estimated time of ovulation (based on ultrasonography), with the milkings recorded between the start of the $\mathrm{AC}$ and the time of ovulation $(\mathrm{n}=17$ cows). Of the 21 cows that displayed behavioral estrus and subsequently ovulated, only 17 cows had an activity cluster and an identified time of ovulation. Estrous behavior was denoted as M (mounting), or S (standing). The interval between the last ultrasound scan of the preovulatory follicle and the first ultrasound scan after ovulation is denoted by the length of the solid bar.

811) did not have a time of ovulation identified. In 2 cows $(10.5 \%$; cow numbers 790 and 791$)$ the interval was short (23 to $25 \mathrm{~h}), 9$ cows $(47.4 \%)$ had a normal interval ( $>25$ to $30 \mathrm{~h}), 5$ cows $(26.3 \%)$ had a long but normal interval ( $>30$ to $35 \mathrm{~h}$ ), and 3 cows $(16 \%)$ had very long intervals ( $>35$ to $43 \mathrm{~h}$; as defined by Bloch et al., 2006). The mean interval from the start of standing estrous behavior to ovulation was $30 \pm 1.1 \mathrm{~h}(\mathrm{n}=19$ cows).

The duration of the estrous-related behavior increased as the mean $\mathrm{E}_{2}$ concentration of the last $8 \mathrm{~h}$ before the start of the LH surge increased $($ F-statistic $=7.21 ; P=$ $0.02 ; \mathrm{R}^{2}=0.28$ ), as the peak $\mathrm{E}_{2}$ increased (F-statistic $\left.=6.31 ; P=0.02 ; \mathrm{R}^{2}=0.25\right)$, as the magnitude of the AUC of the $\mathrm{E}_{2}$ increased (F-statistic $=4.99 ; P=0.04$;
$\mathrm{R}^{2}=0.21$; Figure $3 \mathrm{~A}$ ) and as the AUC of the preovulatory FSH surge decreased (F-statistic $=10.31 ; P=$ $\left.0.005 ; R^{2}=0.36\right)$. The duration of the estrous-related behavior did not change with an increase in magnitude of the AUC of the LH surge (overall F-statistic $=0 ; P$ $=0.98)$. Synchrony between the time of occurrence of estrous-related behavior and the LH surge was noted. All of the estrous-related behavior occurred within the LH surge for $76 \%(16 / 21)$ of cows. Of the remaining 5 cows, 3 cows started their estrous-related behavior $4 \mathrm{~h}$ before the start of the LH surge and 2 cows (cow numbers 670 and 761) started $8 \mathrm{~h}$ beforehand. All cows finished before the end of the LH surge except 1 cow that finished $4 \mathrm{~h}$ after the LH surge finished. The magnitude of the $\mathrm{E}_{2}$ increase was $312 \pm 15$ (range 206-470). 


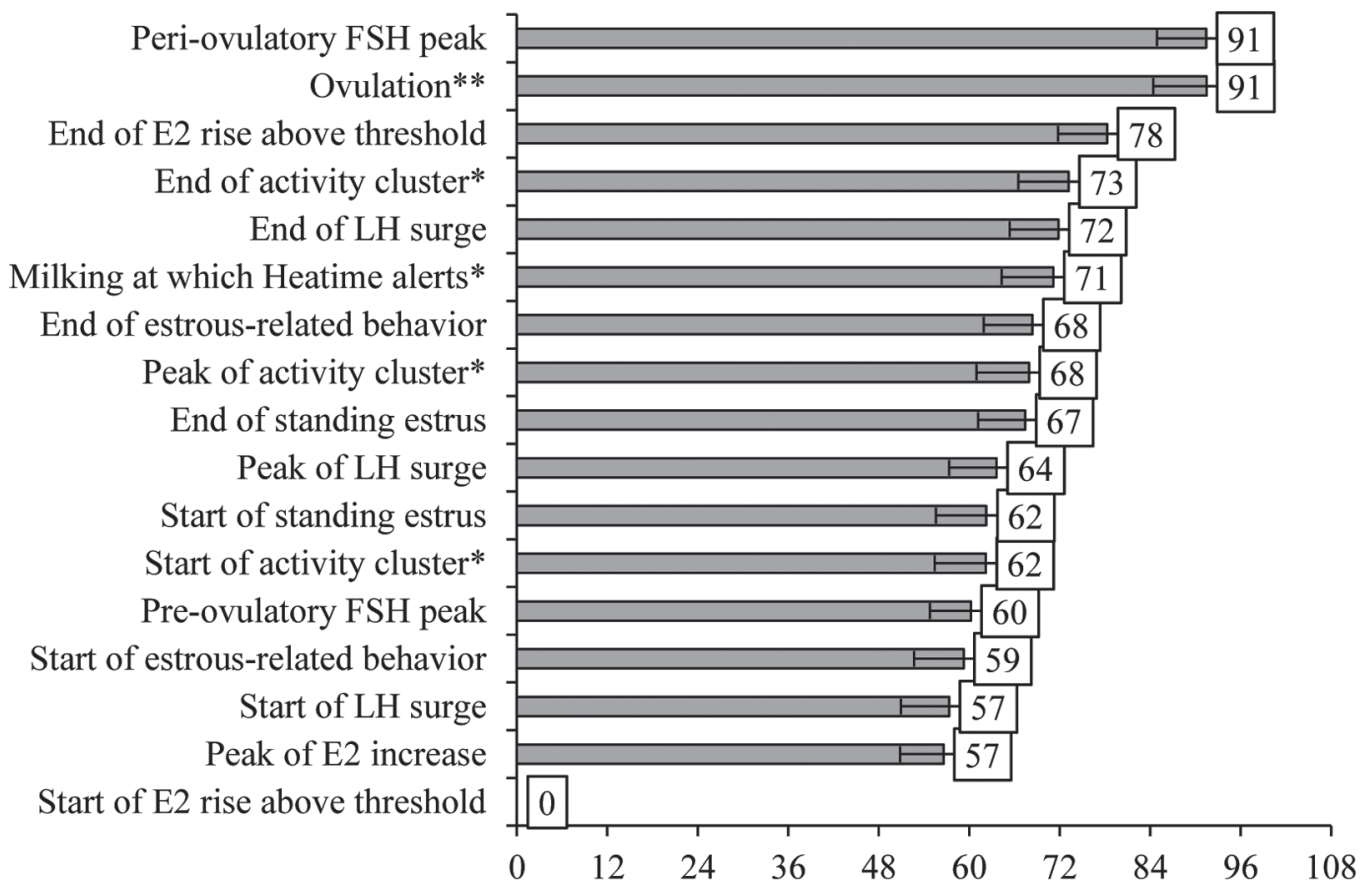

Mean interval from elevation of estradiol-17 $\beta$ to listed events $(\mathrm{h})$

Figure 2. Interval (h) from the elevation of the estradiol-17ß (E2) increase above threshold to the sequence of occurrence of listed endocrine events $[\mathrm{n}=21 ; 17$ cows had both an activity cluster $(\mathrm{AC})$ and an identified time of ovulation, 2 cows had no AC, and another 2 cows had no identified time of ovulation]. Estrous behavior was observed visually or monitored by Heatime (SCR Engineers Ltd., Netanya, Israel). Concentrations of $\mathrm{E}_{2}, \mathrm{LH}$, and FSH in serum were monitored. An asterisk $(*)$ indicates 19 cows had an AC; two asterisks (**) indicate a different set of 19 cows with a known time of ovulation.

The mean $\mathrm{E}_{2}$ concentration of the last $8 \mathrm{~h}$ before the start of the LH surge ranged from 2 to $7 \mathrm{pg} / \mathrm{mL}$ with a median value of $4 \mathrm{pg} / \mathrm{mL}$.

The duration of standing estrous behavior increased as the AUC of the preovulatory FSH surge decreased $\left(\right.$ F-statistic $\left.=4.7 ; P=0.04 ; \mathrm{R}^{2}=0.21\right)$, the mean $\mathrm{E}_{2}$ concentration of the last $8 \mathrm{~h}$ before the start of the LH surge increased $\left(\mathrm{F}\right.$-statistic $=5.44 ; P=0.03 ; \mathrm{R}^{2}=$ 0.22 ), and peak $\mathrm{E}_{2}$ concentrations increased (F-statistic $\left.=5.77 ; P=0.03 ; \mathrm{R}^{2}=0.23\right)$. Cows with higher milk yields had higher preovulatory FSH (AUC) surges (Fstatistic $\left.=5.9 ; P=0.03 ; \mathrm{R}^{2}=0.25\right)$. The shorter the duration of the LH surge, the longer the duration of standing estrus (F-statistic $=4.56 ; P=0.04 ; \mathrm{R}^{2}=$ $0.19)$. There was tight synchrony between the time of occurrence of standing estrus and the LH surge. Ninety percent of cows had all of their standing estrous period during the LH surge. The duration of standing estrus was not affected by increases in the magnitude of the $\mathrm{E}_{2}$ increase (F-statistic $\left.=0.43 ; P=0.52 ; \mathrm{R}^{2}=0.02\right)$, the AUC of the LH surge (overall F-statistic $=0.02$; $P=0.88$ ), or the peak $\mathrm{LH}$ concentration of the surge (F-statistic $=0.04 ; P=0.85)$. The duration of the LH surge was $14.5 \pm 0.9 \mathrm{~h}$ (range $8-24 \mathrm{~h}$ ).

\section{Relationship Between Endocrine Profiles and AC}

The interval from the start of the $\mathrm{E}_{2}$ increase (above threshold) to the time of occurrence of the $\mathrm{AC}$ and other endocrine events for each cow is presented in Figure 2. The peak intensity of the AC occurred after the peak of the LH surge. Four cows had a false positive AC, which occurred before the start of the LH surge. In total, 15 cows had normal endocrine and Heatime activity profiles (Figure 4). Six cows either had abnormal endocrine profiles, no $\mathrm{AC}$, or a false positive $\mathrm{AC}$ occurring; data for 1 cow (cow number 727) with a false positive AC (Figure 5), 1 cow (cow number 728) with no AC (Figure 6), and 1 cow (cow number 754) with a combination of an abnormal endocrine profile and a false positive AC (Figure 7).

The mean peak $\mathrm{E}_{2}$ during the proestrus increase was $7.3 \pm 0.5 \mathrm{pg} / \mathrm{mL}$ (range $4.2-14.5 \mathrm{pg} / \mathrm{mL}$ ). The mean duration of $\mathrm{E}_{2}$ (above threshold) was $78 \pm 6.5 \mathrm{~h}$ (range 40-152 h). The 2 cows that did not have AC had the lowest peak $\mathrm{E}_{2}$ concentrations recorded; that is, 4.4 (cow number 727 ) and $4.2 \mathrm{pg} / \mathrm{mL}$ (cow number 728). No relationship was found between the peak concentration of $\mathrm{E}_{2}$ and the duration of the associated $\mathrm{E}_{2}$ rise (F-statistic 
A

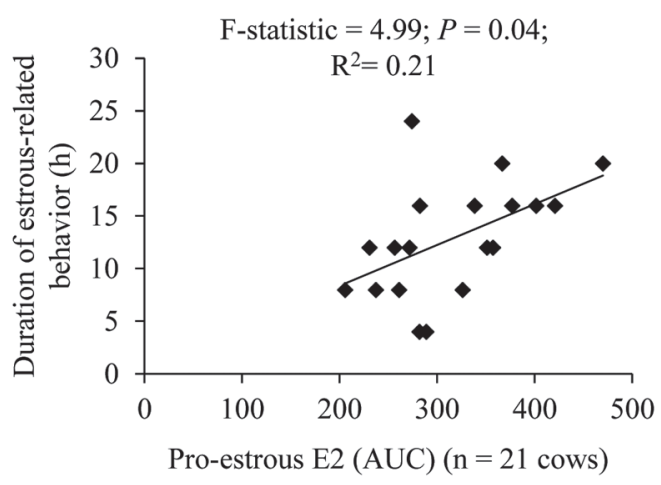

$\mathrm{C}$

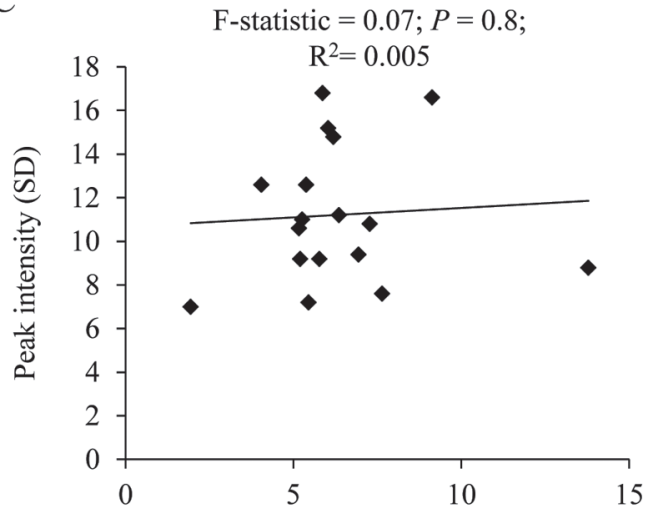

Peak LH concentration of the preovulatory surge $(\mathrm{ng} / \mathrm{mL})$

$(\mathrm{n}=17$ cows $)$

E

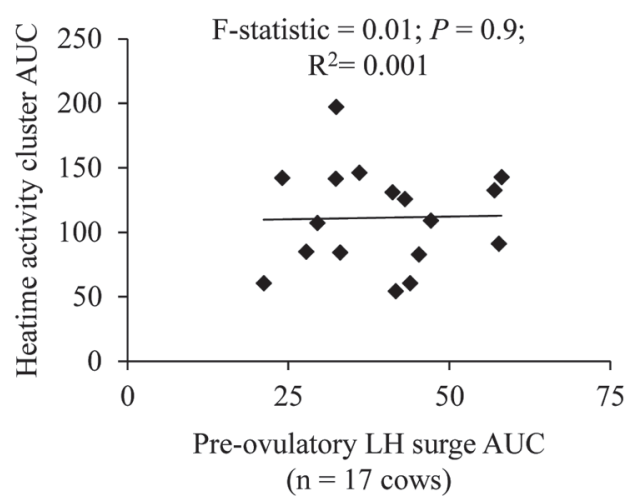

B

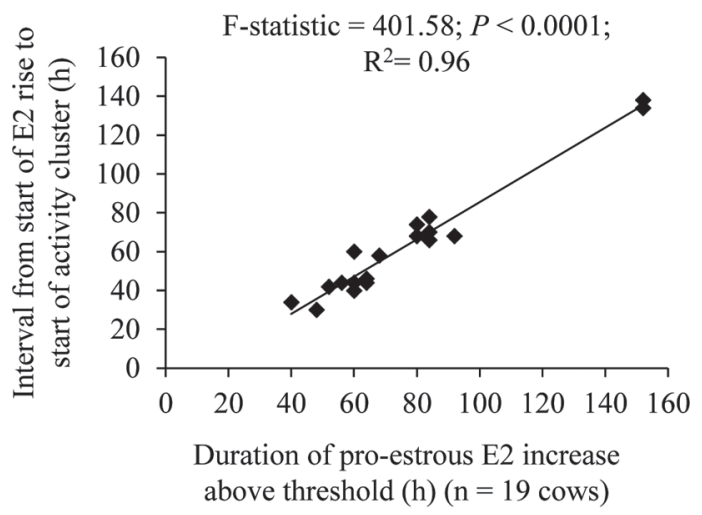

D

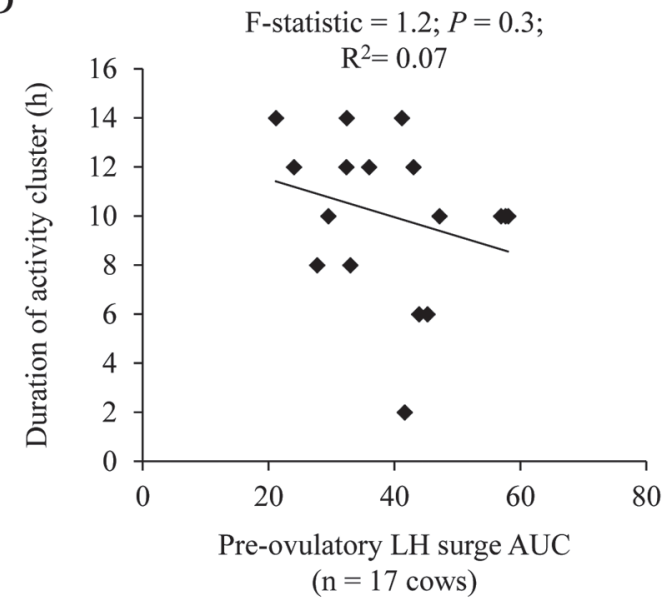

Figure 3. Scatterplots showing a linear relationship between the duration of estrous-related behavior and estradiol-17 (E2) area under the curve (AUC; A); interval from start of E2 increase to start of activity cluster (AC) and duration of E2 increase (B). Scatterplots are shown which do not display a linear relationship between the peak intensity of the $\mathrm{AC}$ and peak LH concentration of the surge $(\mathrm{C})$; the duration of the $\mathrm{AC}$ and the LH surge AUC (D); AC AUC and LH surge AUC (E). Only 19 cows were included in part B, as they had a known time of ovulation. In parts $\mathrm{C}, \mathrm{D}$, and E, 2 outlier data points were removed which results in the remaining data for 17 cows not supporting a relationship between the 2 variables.

$=2.89 ; P=0.11 ; \mathrm{R}^{2}=0.13 ; \mathrm{n}=21$ cows $)$. A longer duration of the proestrous $\mathrm{E}_{2}$ increase had no relationship with the peak intensity of the $\mathrm{AC}(\mathrm{F}$-statistic $=0.32 ; P$ $\left.=0.58 ; \mathrm{R}^{2}=0.02\right)$, the duration of the $\mathrm{AC}$ (F-statistic $\left.=0.29 ; P=0.6 ; \mathrm{R}^{2}=0.02\right)$, or the $\mathrm{AUC}$ of the $\mathrm{AC}$ $\left(\right.$ F-statistic $\left.=2.25 ; P=0.15 ; \mathrm{R}^{2}=0.12\right)$.

The sequence of occurrence of the interval from the start of an AC to the key hormonal events was the same 


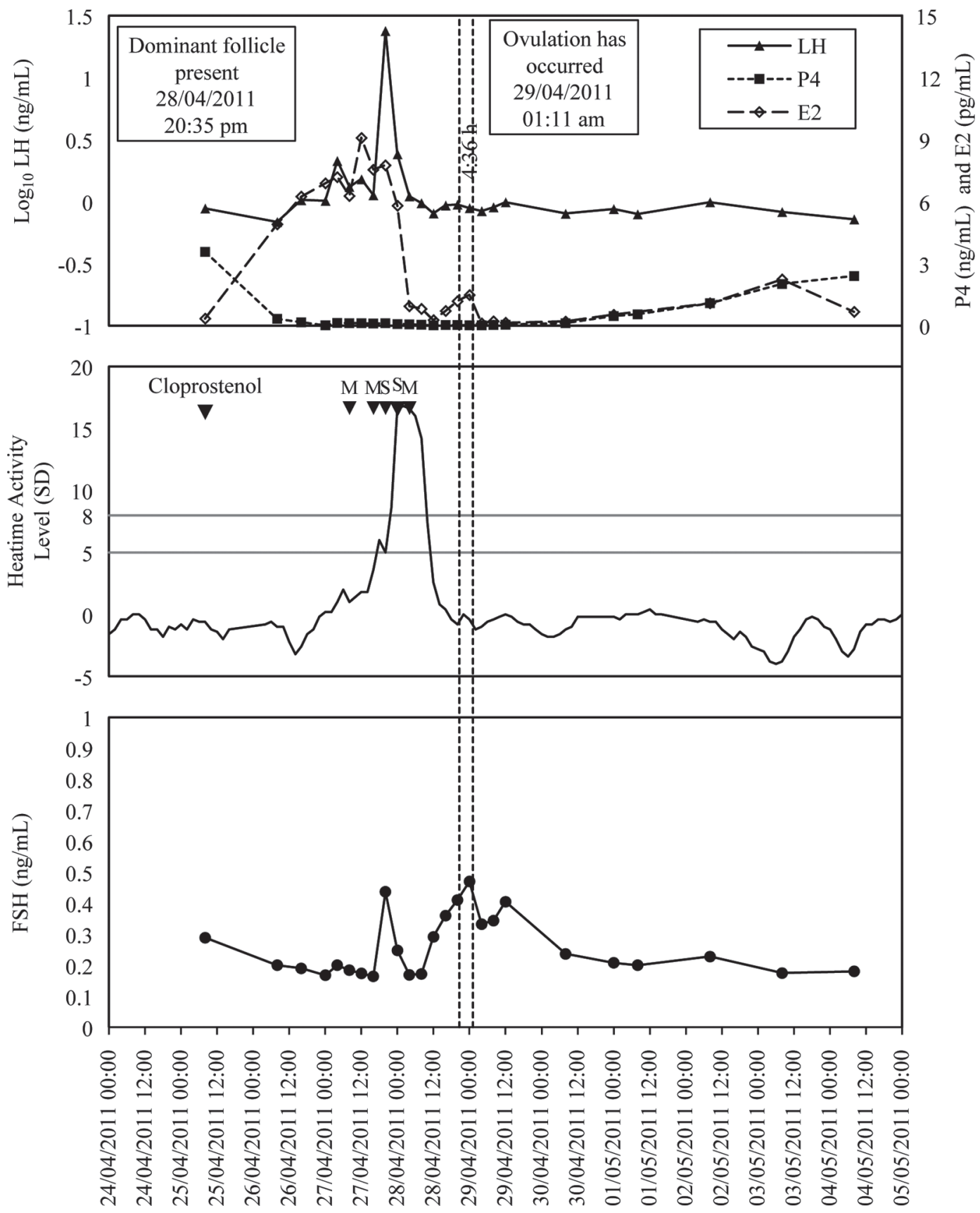

Figure 4. A case study of a cow displaying normal serum profiles of estradiol-173 (E2), FSH, LH, and progesterone (P4) during both the preovulatory phase and up to d 6 in the luteal phase of the estrous cycle with concurrent monitoring of physical activity by Heatime (SCR Engineers Ltd., Netanya, Israel) and by visual behavioral observation (cows). Estrous behavior was denoted as M (mounting) or S (standing). Time during which ovulation occurred is marked by two vertical dashed lines.

for all cows evaluated (Figure 8A). The average time of occurrence of both the peak of the LH surge and the preovulatory FSH peak was $1 \mathrm{~h}$ before the start of an AC. The AC started after the start of the LH preovulatory surge in $95 \%(18 / 19)$ cows. The remaining cow started at the same time as the start of the LH surge.
Cows with a longer duration of $\mathrm{E}_{2}$ increase (above threshold) had longer intervals from the onset of the $\mathrm{E}_{2}$ increase (above threshold) to the start of the $\mathrm{AC}$ $\left(\right.$ F-statistic $=401.58 ; P<0.0001 ; \mathrm{R}^{2}=0.96 ;$ Figure $3 \mathrm{~B})$ and to the start of standing estrus (F-statistic $=$ 465.50; $\left.P<0.0001 ; \mathrm{R}^{2}=0.96\right)$. The duration of stand- 


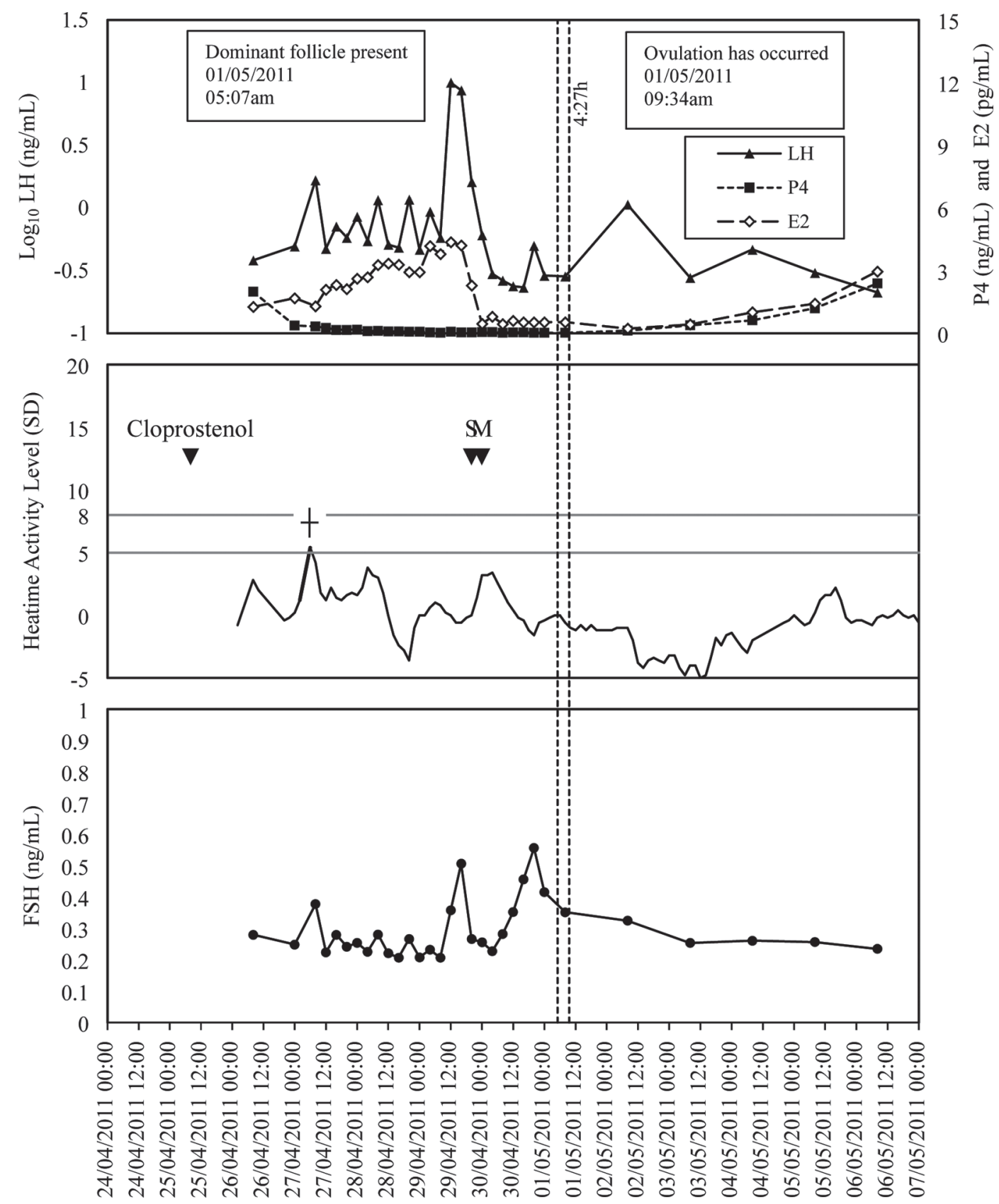

Figure 5. The endocrine profiles, estrous behavior, and Heatime (SCR Engineers Ltd., Netanya, Israel) activity data for cow number 727 , which had a false positive cluster $(+)$ but did not have a correct activity cluster (AC) after the start of the preovulatory luteinizing (LH) surge. Time during which ovulation occurred is marked by two vertical dashed lines. E2 = estradiol-17 $\beta$; P4 = progesterone.

ing estrus increased as the interval from the start of the $\mathrm{E}_{2}$ rise (above threshold) to the start of the $\mathrm{AC}$ increased $\left(F=4.77 ; P=0.04 ; \mathrm{R}^{2}=0.22\right)$. A weak association was found between a longer interval from the start of the proestrous $\mathrm{E}_{2}$ rise to the start of the $\mathrm{AC}$ and a greater magnitude of $\mathrm{E}_{2}$ (AUC) during the proestrous rise $\left(\right.$ F-statistic $\left.=3.21 ; P=0.09 ; \mathrm{R}^{2}=0.16\right)$.
The peak intensity of the $\mathrm{AC}$ did not change when either the magnitude of the $\mathrm{E}_{2}$ increase (AUC; F- statistic $\left.=0.13 ; P=0.72 ; \mathrm{R}^{2}=0.01\right)$ or the peak $\mathrm{E}_{2}$ $\left(\right.$ F-statistic $\left.=1.11 ; P=0.3 ; \mathrm{R}^{2}=0.06\right)$ increased. The peak intensity of the AC occurred after the peak of the LH surge $(6.6 \pm 0.8 \mathrm{~h})$. The peak intensity of the AC did not change when either the magnitude of the LH 


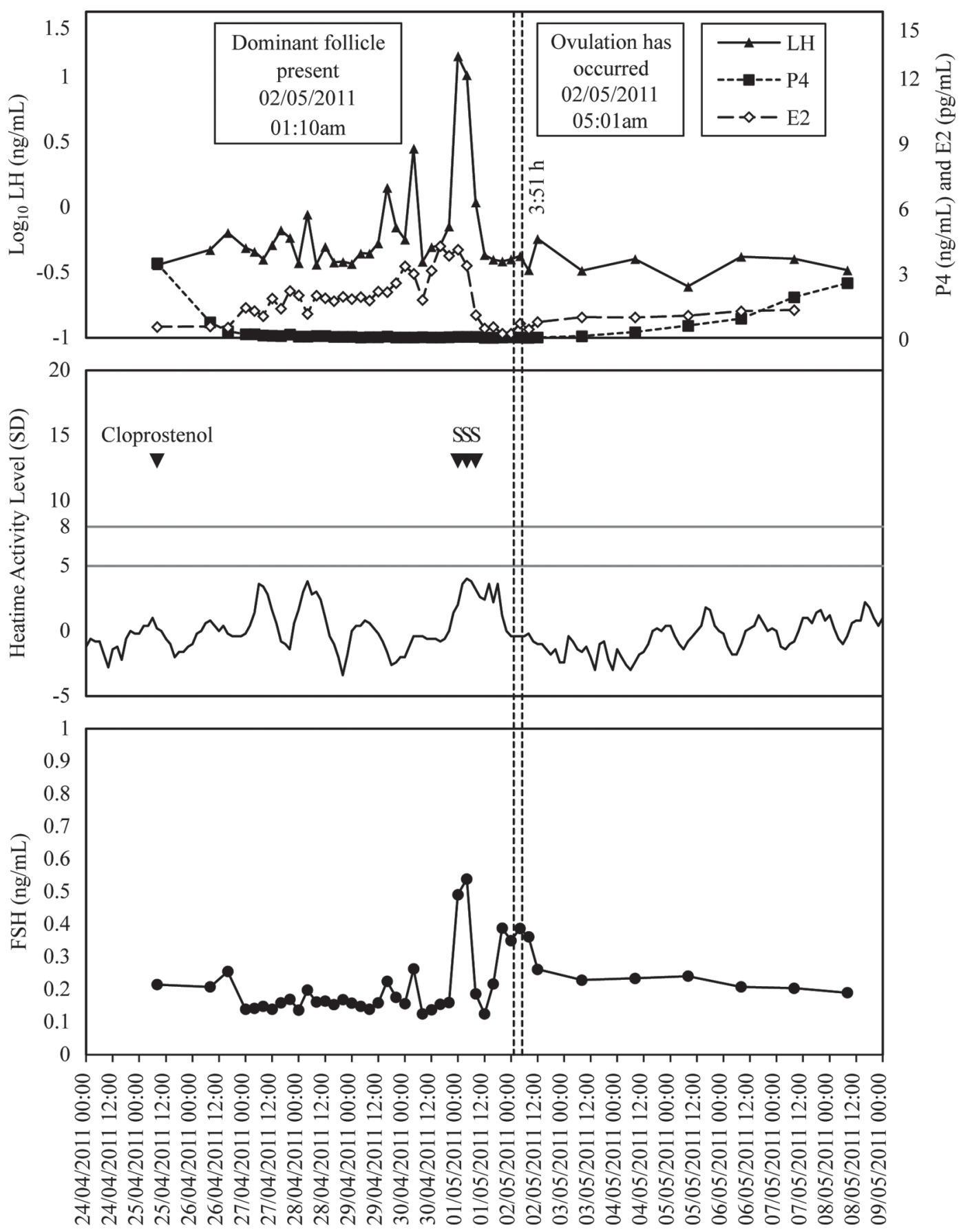

Figure 6. The endocrine profiles, estrous behavior, and Heatime (SCR Engineers Ltd., Netanya, Israel) activity data of cow 728 , which did not have a correct activity cluster (AC) after the start of the preovulatory LH surge. Time during which ovulation occurred is marked by two vertical lines. $\mathrm{E} 2=$ estradiol-17 $\beta ; \mathrm{P} 4=$ progesterone.

surge increased $\left(\mathrm{F}\right.$-statistic $\left.=0.74 ; P=0.4 ; \mathrm{R}^{2}=0.05\right)$, the duration of the surge $(\mathrm{F}$-statistic $=1.97 ; P=0.2$; $\mathrm{R}^{2}=0.1$ ) or the peak concentration of the LH surge increased (F-statistic $=0.07 ; P=0.8 ; \mathrm{R}^{2}=0.005$; Figure $3 \mathrm{C})$. The peak intensity of the $\mathrm{AC}$ did not change when either the magnitude of the FSH surge (F-statistic =
1.09; $\left.P=0.3 ; \mathrm{R}^{2}=0.06\right)$, the duration of the surge $\left(\right.$ F-statistic $\left.=0.83 ; P=0.4 ; \mathrm{R}^{2}=0.05\right)$, or the peak concentration of the FSH surge increased (F-statistic $=$ $0.004 ; P=0.95 ; \mathrm{R}^{2}=0.0002$ ).

The duration of the AC did not change when either the magnitude of the LH surge $(\mathrm{F}$-statistic $=1.2 ; P=$ 


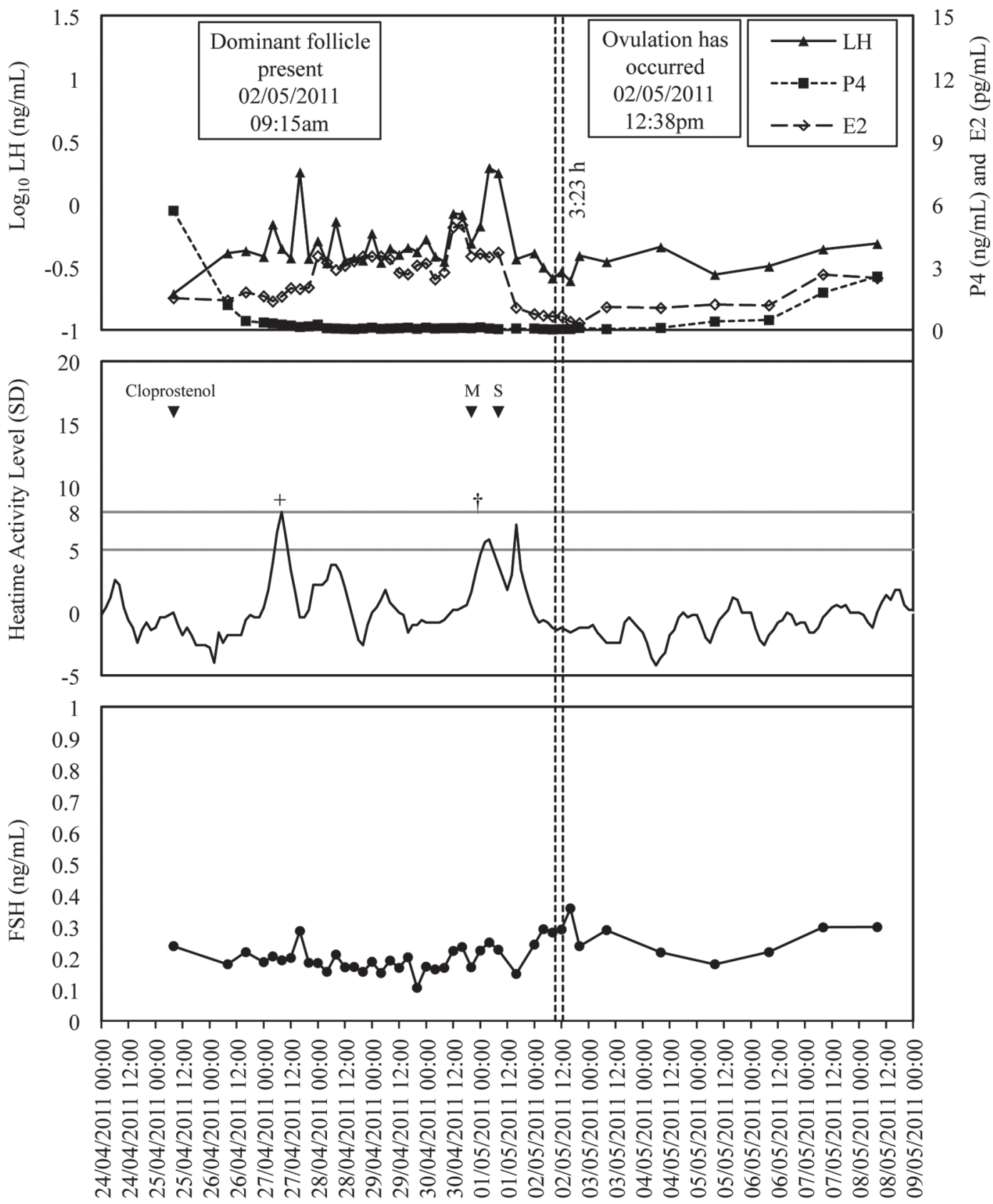

Figure 7. An endocrine profile of cow 754 indicating a poor LH surge with no concomitant preovulatory FSH surge. The first of 2 activity clusters (AC) during the preovulatory phase were a false positive cluster $(+)$. The second AC occurred at the correct time $(\dagger)$. Estrous behavior was denoted as M (mounting), or S (standing). Time during which ovulation occurred is marked by two vertical dashed lines. E2 = estradiol-17 $\beta$; P4 = progesterone; Heatime (SCR Engineers Ltd., Netanya, Israel).

$0.3 ; \mathrm{R}^{2}=0.07 ;$ Figure 3D), the duration of the surge $\left(\right.$ F-statistic $\left.=0.001 ; P=0.98 ; \mathrm{R}^{2}=5.9 \mathrm{E}-05\right)$, or the peak LH concentration of the preovulatory surge increased (F-statistic $\left.=0.47 ; P=0.5 ; \mathrm{R}^{2}=0.03\right)$. The duration of the overlap between the start of the $\mathrm{AC}$ and the end of the LH surge ranged between 0 and 14 $\mathrm{h} ; 1$ cow had no overlap as the AC started at the same time as the LH surge ended. Of the 19 cows that had an
$\mathrm{AC}$, the LH surge ended before the end of the activity cluster in $79 \%(15 / 19)$ of cows and at the same time in the remaining 4 cows. The duration of the $\mathrm{AC}$ did not increase with increases in either the duration of the $\mathrm{E}_{2}$ increase above threshold, (F-statistic $=0.29 ; P=$ $\left.0.6 ; \mathrm{R}^{2}=0.02\right)$, the magnitude of the AUC of the $\mathrm{E}_{2}$ increase above threshold, (F-statistic $=0.28 ; P=0.6$; $\left.\mathrm{R}^{2}=0.02\right)$, the concentration of peak $\mathrm{E}_{2}(\mathrm{~F}$-statistic $=$ 
A

$$
\text { Peri-ovulatory FSH peak }
$$

Last E2 record above threshold

End of LH surge

End of estrous-related behavior

End of standing estrous behavior

Start of activity cluster

Peak of LH surge

Pre-ovulatory FSH peak

Start of standing estrous behavior

Start of estrous-related behavior

$$
\begin{array}{r}
\text { Start of LH surge } \\
\text { Peak of E2 increase }
\end{array}
$$

First E2 record above threshold

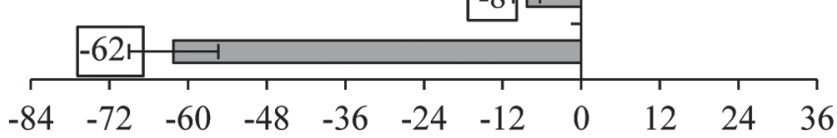

Mean interval from the start of the activity cluster to listed events (h)

B

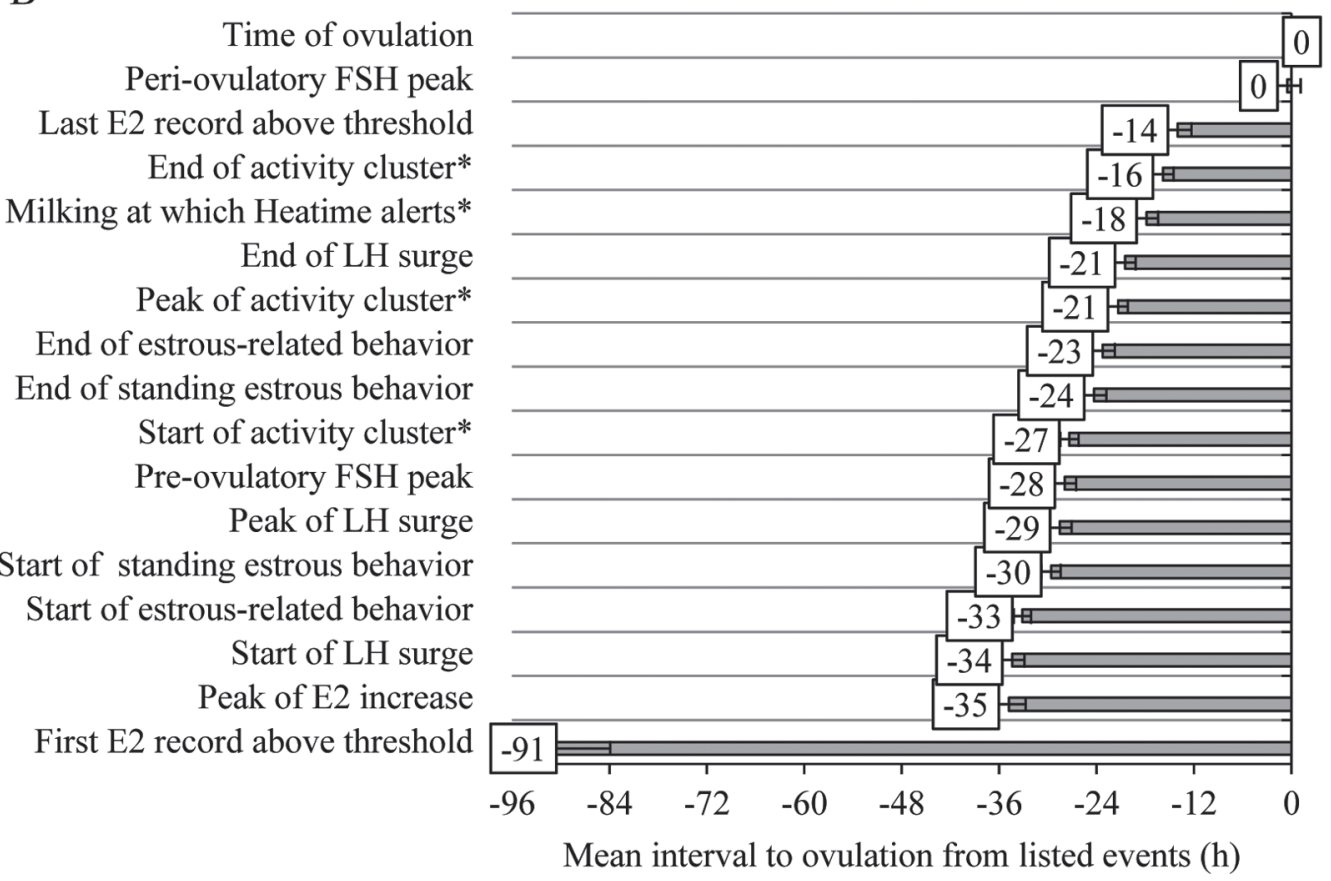

Figure 8. Chronology between $(\mathrm{A})$ the start of the activity cluster $(\mathrm{AC} ; \mathrm{n}=19 \mathrm{cows})$ and $(\mathrm{B})$ the time of ovulation to listed events $(\mathrm{n}=19$ cows). All data points are rounded to the nearest whole value. Only 17 cows had both an AC and an identified time of ovulation, 2 cows had no $\mathrm{AC}$, and another 2 cows had no identified time of ovulation. E2 = estradiol-173; Heatime (SCR Engineers Ltd., Netanya, Israel).

$0.16 ; P=0.7 ; \mathrm{R}^{2}=0.01$ ), or the mean concentration of $\mathrm{E}_{2}$ in the last $8 \mathrm{~h}$ before the start of the LH surge $\left(\right.$ F-statistic $\left.=1.36 ; P=0.3 ; \mathrm{R}^{2}=0.07\right)$. The duration of the $\mathrm{AC}$ did not change when either the magnitude of the FSH preovulatory surge (F-statistic $=0.15 ; P=$ $\left.0.7 ; R^{2}=0.009\right)$, the duration of the surge (F-statistic 
$\left.=0.8 ; P=0.4 ; \mathrm{R}^{2}=0.05\right)$, or the peak FSH concentration of the surge $\left(\mathrm{F}\right.$-statistic $=1.6 ; P=0.22 ; \mathrm{R}^{2}=$ 0.09) increased.

An increase in the magnitude (AUC) of the preovulatory LH surge was not associated with a corresponding increase in the magnitude (AUC) of the AC (F-statistic $=0.01 ; P=0.9 ; \mathrm{R}^{2}=0.001 ;$ Figure $\left.3 \mathrm{E}\right)$. Similarly, an increase in the magnitude of the preovulatory FSH surge was not associated with a corresponding increase in the magnitude of the $\mathrm{AC}$ (F-statistic $=0.18 ; P=$ $0.68 ; R^{2}=0.01$. No evidence was found to suggest that a larger preovulatory dominant follicle was associated with a higher magnitude of proestrous $\mathrm{E}_{2}$, (F-statistic $\left.=2.85 ; P=0.11 ; \mathrm{R}^{2}=0.14\right)$. Higher concentrations of $\mathrm{E}_{2}$ (AUC) were not associated with a greater $\mathrm{AC}$ (AUC) magnitude $\left(\right.$ F-statistic $=0.0 ; P=0.99 ; \mathrm{R}^{2}=$ $0.0)$.

\section{Predicting the Time of Ovulation Based on the Characteristics of the AC}

The chronology from the time of ovulation to different hormonal events and estrous-related behavior was the same for all cows in the trial (Figure 8B). On average, the periovulatory FSH peak was found to occur at the same time as ovulation, based on ultrasonography $(t$-test $=0.31 ; P=0.76 ; \mathrm{n}=19$ cows; Figure $8 \mathrm{~B})$. Both the peak of the LH surge and the preovulatory FSH peak occurred, on average, at a similar interval before ovulation $(28.5 \pm 1.4$ vs. $27.9 \pm 1.4 \mathrm{~h})$. The mean interval between the onset of the LH surge and ovulation was $34.4 \pm 1.5 \mathrm{~h}$ and between the end of the LH surge and ovulation was $20.5 \pm 1.3 \mathrm{~h}$. The mean interval between the peak serum $\mathrm{E}_{2}$ concentration and time of ovulation was $34.8 \pm 2.1 \mathrm{~h}$. The mean was 0.4 $\pm 0.03 \mathrm{ng} / \mathrm{mL}$ (range $0.2-0.7 \mathrm{ng} / \mathrm{mL}$ ) for the preovulatory FSH peak and $0.5 \pm 0.02 \mathrm{ng} / \mathrm{mL}(0.3-0.7 \mathrm{ng} / \mathrm{mL})$ for the periovulatory FSH peak.

The period from identification of the start of an AC to the time of estimated ovulation was mapped out along with the times of the morning and afternoon milkings and the 12- to 18-h window before ovulation during which insemination was recommended (Figure 1). The mean interval from the start of an $\mathrm{AC}$ to ovulation was $27 \pm 1 \mathrm{~h}$ (median $=27 \mathrm{~h}$; range $21-39 \mathrm{~h})$. No association was found between the interval from the start of an $\mathrm{AC}$ to the time of ovulation with either the peak intensity or duration of the AC (overall F-statistic $=1.01 ; P=0.33 ; \mathrm{n}=17$ cows). There was also no change found in the interval from the peak of an $\mathrm{AC}$ to ovulation with a change in the peak intensity or a change in the duration of a cluster (overall F-statistic $=0.26 ; P=0.8 ; \mathrm{R}^{2}=0.04 ; \mathrm{n}=17$ cows $)$.
A model prediction for the interval from the end of the cluster to ovulation showed that as the duration of an AC increased, the interval from the end of the cluster to ovulation decreased (F-statistic $=9.66 ; P=$ $0.007 ; \mathrm{R}^{2}=0.39 ; \mathrm{n}=17$ cows). The equation for the model prediction when both replicates were amalgamated was:

$$
\begin{aligned}
& \operatorname{Ln}(\text { interval to ovulation })=3.3-0.05 \\
& \times(\text { duration of cluster })
\end{aligned}
$$

The prediction could either overestimate the interval to ovulation by up to $6 \mathrm{~h}$ or underestimate it by up to 5 $\mathrm{h}$ compared with the actual interval to ovulation based on ultrasonography $(\mathrm{n}=16$ cows). For 1 outlier the interval was underestimated by $13 \mathrm{~h}$.

\section{DISCUSSION}

One of the main factors influencing reproductive efficiency in dairy cows is poor estrous-detection rates. Observation of cows standing to be mounted is considered to be the gold standard for identification of cows in estrus (Van Eerdenburg et al., 1996). However, only about $50 \%$ of cows will express this sign (Lyimo et al., 2000; Roelofs et al., 2006) or it may not be detected due to the duration of standing estrus being too short or occurring during the night. Thus, an automated monitor would be ideal for accurate identification of estrous cows throughout the 24-h day. The monitor should accurately identify cows in estrus to facilitate identification of the correct time to inseminate cows based on the interval from the onset of the $\mathrm{AC}$ to the expected time of ovulation. In a recent study with Heatime and using the same commercial settings as the present study, $72 \%$ of estrous periods were correctly identified with $32 \%$ false positive clusters occurring (Aungier et al., 2012). In our study, Heatime successfully detected $90 \%(19 / 21)$ of cows in estrus and missed $10 \%(2 / 21)$ of cows in estrus. It incorrectly identified $17 \%(4 / 23)$ of the total number of AC. These false positive clusters occurred when other cows were on record as displaying estrous behavior. The improved results in our study were due to the fact that only cows visually identified in standing estrus were included in the analysis.

The AC duration lasted, on average, $2 \mathrm{~h}$ longer than the average duration of standing estrus and $2 \mathrm{~h}$ less than the total estrous-related activity (mounting and standing). The 2-h time lag between the end of the AC and the end of the estrous-related behavior arose due to the algorithm used by Heatime or some activity being in a 2-h block, but the average of the block was still below the 5-SD peak activity threshold. 
Our study found that cows with a longer duration of estrous-related behavior had a longer AC duration $(P$ $=0.09$ ). The peak intensity of an AC did not increase with an increase in the duration of estrous-related behavior. The poor association may be due to the small sample size. Roelofs et al. (2005b) used a pedometer to record the number of steps taken by cows at 2-h intervals. The duration of estrous-related behavior was, on average, $2 \mathrm{~h}$ longer than the pedometer-defined estrus, but the duration of the pedometer estrus was positively correlated with both estrous-related behavior $(\mathrm{r}=0.53)$ and with standing estrus $(\mathrm{r}=0.38 ; P<0.05)$. In the present study, the 2 cows, cow numbers 727 and 728 , that did not have an $\mathrm{AC}$ displayed estrous behavior but failed to reach the 5-SD threshold to trigger the start of an AC.

The present study agrees with previous research that suggests that $\mathrm{E}_{2}$ may trigger an intermediate step that is involved in regulation of sexual behavior in cows. The delay in the onset of estrous-related behavior after the start of the proestrous $\mathrm{E}_{2}$ increase confirmed previous research results (Van Eerdenburg et al., 2000). The fact that $15 \mathrm{~h}$ before the start of standing estrus $\mathrm{E}_{2}$ concentrations $>80 \%$ of peak concentrations had been previously observed (Lyimo et al., 2000; Van Eerdenburg, 2008). Van Eerdenburg (2008) suggested that the timing of these high $\mathrm{E}_{2}$ concentrations was required to upregulate the number of GnRH receptors in the pituitary gland (Schoenemann et al., 1985; Gümen and Wiltbank, 2002) and thus induce the GnRH and LH surges. A specific isoform of $\mathrm{GnRH}$ has been identified in cattle (Yahalom et al., 1999) and may be involved in regulation of sexual behavior in the midbrain central gray and the medial preoptic area of the brain (Terasawa and Davis, 1983; Jennes et al., 1997).

The $\mathrm{E}_{2} \alpha$-receptors have been identified as being involved in the regulation of sexual behavior in the female rat (Rissman et al., 1997). Prior exposure to $\mathrm{P}_{4}$ may increase functional $\mathrm{E}_{2} \alpha$-receptors in the mediobasal hypothalamus, an area that is critical for inducing the GnRH surge. The receptors disappear from the hypothalamus of cows during estrus (Van Eerdenburg et al., 2000). This could explain our study's result that estrous-related behavior was still being recorded in $90 \%(19 / 21)$ of cows as proestrous $\mathrm{E}_{2}$ concentrations decreased, as previously described (Van Eerdenburg, 2008).

During the present study, the magnitude of the LH surge (AUC) did not increase with an increase in proestrous $\mathrm{E}_{2}$ concentration. Previously it was observed that, once the LH surge was triggered, only a certain concentration of LH was available for release regardless of the concentration of $\mathrm{E}_{2}$ produced (Haughian et al., 2004). The present study observed a tight synchrony between the time of occurrence of standing estrus with the time of the LH surge, as previously described (Stoebel and Moberg, 1982; Dieleman et al., 1986; Van Eerdenburg, 2008). This supports the previous finding that even with high $\mathrm{E}_{2}$ concentrations cows only showed estrous behavior when an LH surge was present (Martin et al., 1978). It also supports the fact that cows are most receptive just coming up to the time of ovulation. This will allow time for the semen to mature and become capacitated. The semen will then be able to fertilize the oocyte which will ovulate within $24 \mathrm{~h}$ of the LH surge (Van Eerdenburg, 2008).

Duration of the LH surge is normally shorter and is out-lived by the GnRH surge by a further 4 to 8 $\mathrm{h}$ in sheep (Karsch and Evans, 1996). Prolonged increases in GnRH may be related to the maintenance of sexual receptivity around the time of ovulation in ewes, long after being initiated by $\mathrm{E}_{2}$ (Caraty et al., 2002). Our observation that a shorter-lasting LH surge was observed with a longer-lasting standing estrus would add support to this suggestion. The GnRH was identified in the cerebrospinal fluid of cattle (Gazal et al., 1998; Yoshioka et al., 2001; Rizzo et al., 2011); GnRH administered intracerebroventricularly induced sexual receptivity in sheep. The duration of this receptivity corresponded closely to the duration of the GnRH surge in the cerebrospinal fluid (Caraty and Skinner, 2008).

Cows with longer durations of the proestrous $\mathrm{E}_{2}$ increase had longer intervals between the start of the proestrous $\mathrm{E}_{2}$ increase and both the start of standing estrus and the start of the AC. These findings support the suggestion that an intermediate step exists between the time of increased proestrous $\mathrm{E}_{2}$ concentrations and the time of estrous behavior (Van Eerdenburg, 2008). If $\mathrm{E}_{2}$ concentration was the sole instigator of the initiation of estrous behavior the AC start would have begun earlier, closer to the period of peak intensity of estrous behavior, namely standing estrus. However, our study observed that a longer duration of standing estrus was associated with an increased interval from the start of the $\mathrm{E}_{2}$ increase to the start of the AC.

When higher proestrous peak $\mathrm{E}_{2}$ concentrations occurred the durations of standing estrus were longer. However, in 19 of the 21 cows studied, estrous-related behavior (mounting other cows and standing to be mounted) was still being observed after the proestrous increase in $\mathrm{E}_{2}$ started to decline; for 14 of these cows standing estrus was the last activity recorded. A longer duration of standing estrus also occurred when the duration of the LH surge, induced by GnRH, was shorter. This finding is in agreement with the suggestion that the continued increase in GnRH after the LH surge ends may be related to the maintenance of sexual behavior around the time of ovulation in ewes (Caraty et al., 
2002). The current study found a temporal relationship between the preovulatory LH surge, standing estrous behavior, and the occurrence of an $\mathrm{AC}$ with the peak of the LH surge preceding the peak of the AC. These findings add support to the suggestion that GnRH has 2 functions. First, to create a preovulatory LH surge that is required for ovulation of the dominant follicle. Second, to induce standing estrous behavior once $\mathrm{E}_{2}$ has activated the $\mathrm{GnRH}$ receptors in the pituitary before the LH surge (Schoenemann et al., 1985), thus facilitating mating to occur (Van Eerdenburg, 2008).

The characteristics of both the preovulatory FSH surge and periovulatory FSH increase, observed during the current study, were similar to those reported in other studies (Sunderland et al., 1994; Haughian et al., 2004). In the present study, the 2 increases were separated by a distinct nadir in FSH concentrations. Thus, each increase was distinct and probably resulted from separate mechanisms. All ovulations were also found to occur during the period of the periovulatory FSH increase as previously described (Dobson, 1978). Except for 1 cow that did not have a preovulatory FSH surge, a coincident increase in both the LH surge and the preovulatory FSH surge occurred in all other cows, as previously described (Schwartz and McCormack, 1972; Sunderland et al., 1994). In our study, as the magnitude of the preovulatory FSH (AUC) surge increased, the magnitude of the LH surge also increased. This suggests that both are stimulated to a similar extent by the GnRH surge.

The specific function of the preovulatory FSH surge is currently unknown. One cow in the current study did not have a preovulatory FSH surge but still ovulated (Figure 7). This suggests that the occurrence of the preovulatory FSH surge is not a prerequisite for the successful outcome of ovulation in all animals. A similar finding was observed in a previous study (D'Occhio et al., 1998). Both LH and FSH receptors, their mRNA, and their protein have been identified in the bovine cervix. One study found that LH receptor expression was high in the cervix during the luteal phase and low during the follicular phase (Mizrachi and Shemesh, 1999). Maximal expression of FSH receptor protein and its corresponding mRNA were high in the cervix at the time of the preovulatory FSH peak (Shemesh et al., 2001). The FSH induced an increase in cervical cyclooxygenase. The increase in cyclo-oxygenase was associated with an increase in cervical prostaglandin (PG) $\mathrm{E}_{2}$ production; $\mathrm{PGE}_{2}$ production has been shown to be responsible for cervical relaxation at estrus (Duchens et al., 1993).

In the present study, cows with greater milk yields had increased concentrations of FSH (AUC) during the preovulatory FSH surge. It is well established that in- verse relationships exist between $\mathrm{E}_{2}$ concentrations and FSH during emergence of follicular waves (Sunderland et al., 1994; Kaneko et al., 2002). However, no studies have examined the relationship between the proestrous increase in $\mathrm{E}_{2}$ and the magnitude of the preovulatory FSH surge. The present study found that as the average concentration of $\mathrm{E}_{2}$ increased (in the last $8 \mathrm{~h}$ before the start of the LH and FSH preovulatory surges) the duration of estrous-related behavior also increased. Therefore, it was not unexpected to find that the lower the magnitude of the preovulatory FSH (AUC) surge, the longer the duration of estrous-related behavior.

The determination of the time of occurrence of ovulation is a critical component in obtaining high fertility rates to AI in dairy cows. Previous research has identified that the recommended time to inseminate is during the 12 - to 18 -h interval before ovulation. This is to ensure both a higher fertilization rate and a higher embryo survival rate (Hunter, 1994). Other studies have confirmed that endocrine profiles can be used in the prediction of the timing of ovulation (Rajamahendran et al., 1989). The peak in the LH surge was previously found to occur $29 \pm 1.5 \mathrm{~h}$ before ovulation (based on ultrasonography at 4-h intervals; Saumande and Humblot, 2005). This result was similar to the $28.5 \pm 1.4$ $\mathrm{h}$ obtained in the present study. Another study found that the interval between the onset of the LH surge and ovulation was $27.3 \pm 1.6 \mathrm{~h}$ and between the end of the LH surge and ovulation was $17.5 \pm 1.5 \mathrm{~h}$ (Bernard et al., 1983). In that study, the time of ovulation was determined by using laparoscopy, which was performed $4 \mathrm{~h}$ before the estimated time of ovulation but was continued until ovulation ( 2 to $7 \mathrm{~h}$ ) later. The animals used were Holstein heifers $(\mathrm{n}=12)$ between 12 and 30 mo of age. These factors could contribute to the deviation from the present study, where both the interval from the onset of the LH surge to ovulation $(34.4 \pm 1.5 \mathrm{~h})$ and the interval from the end of the surge to ovulation were both longer $(20.5 \pm 1.3 \mathrm{~h})$. Whereas the LH surge could therefore be used as a predictor of ovulation time, it would not be practical due to the requirement of blood sampling every $4 \mathrm{~h}$ to identify the onset of the surge. The LH profile cannot be determined from milk samples (Johnson and Reeves, 1988). There has been poor agreement between other studies that examined the interval from peak $\mathrm{E}_{2}$ to the time of ovulation. Much of this lack of agreement is due to the low frequency at which the time of ovulation was determined. Two studies that determined the average interval from the peak plasma $\mathrm{E}_{2}$ concentration to ovulation to be $22.3 \pm$ $1.2 \mathrm{~h}$ in heifers (Mosher et al., 1990) and $30.7 \pm 6.3 \mathrm{~h}$ in cows (Lopez et al., 2002). The latter study would have been less accurate in the determination of the interval to ovulation. Ultrasonography of the preovulatory fol- 
licle ( $\mathrm{n}=17$ cows) was carried out only once daily and ovulation was said to have occurred at the midpoint between 2 consecutive scans, during which time the preovulatory follicle disappeared. In the former study, conversely, laparoscopy ( $\mathrm{n}=6$ heifers) was used at 4 -h intervals until ovulation occurred. These factors would influence the determination of the interval to ovulation and would explain the difference in the result obtained in the present study of $34.8 \pm 2.1 \mathrm{~h}$. Currently, $\mathrm{E}_{2}$ can be detected in full-fat milk samples (Pape-Zambito et al., 2010). However, measurement of this hormone has not been automated for use in practice. It would not be a suitable on-farm technique, as milkings are normally only carried out twice daily.

The present study examined the use of the characteristics of $\mathrm{AC}$ to determine the accuracy with which the time of ovulation could be predicted. The results identified a model based on the interval from the end of an $\mathrm{AC}$ to the time of ovulation. Overestimation of the time of ovulation by up to $6 \mathrm{~h}$ would mean that insemination could occur $6 \mathrm{~h}$ before ovulation. The model could underestimate by up to $5 \mathrm{~h}$ which would mean that an insemination could occur as early as $23 \mathrm{~h}$ before the actual ovulation. In a previous study, where cows were inseminated between 12 and $24 \mathrm{~h}$ before ovulation, $67.7 \%$ of 7 -d-old embryos collected were of good quality (Roelofs et al. 2006). This reduced to $41.4 \%$ between 12 and $0 \mathrm{~h}$ before ovulation. To determine the accuracy of the model prediction, a comparison was made between the actual 12- to 18-h interval before ovulation, as determined by ultrasonography, with the 12 to $18-\mathrm{h}$ interval before ovulation as determined by the model. The mean time of overlap between the model prediction and the actual 12- to 18-h interval was $3.2 \pm 0.5 \mathrm{~h}$. Knowing the mean interval to ovulation along with the time of the start of an $\mathrm{AC}$ can be useful to identify the time of the 12- to $18 \mathrm{~h}$-window before ovulation for AI. Or, if cows have just finished an AC according to the Heatime alert, then the model can be used to make a prediction of the ovulation time.

\section{CONCLUSIONS}

In conclusion, the results show that (1) the start of estrous-related behavior and standing estrus began, on average, 6 and $3 \mathrm{~h}$, respectively, before the start of an $\mathrm{AC}$, and finished, on average, 3 and $2 \mathrm{~h}$, respectively, after the start of the AC; (2) no relationship was found between a higher $\mathrm{E}_{2}$ (AUC) concentration and a larger preovulatory follicle or a bigger AC (AUC); (3) data on the timing of the proestrous $\mathrm{E}_{2}$ increase and the timing of estrous activity suggests that the relationship between them may be mediated by other factors (e.g., the GnRH surge); (4) higher-milk-yielding cows had higher preovulatory FSH surges, which in turn may be linked to shorter durations of both estrous-related behavior and standing estrus; (5) synchrony between the timing of the preovulatory LH surge, estrous-related and standing estrous behavior, and the $\mathrm{AC}$ was observed; (6) an increase in AC duration, but not peak intensity, did occur with longer durations of estrousrelated behavior; (7) no association was found between the $\mathrm{AC}$ characteristics with either the $\mathrm{E}_{2}$, LH, or FSH profiles examined; and (8) the interval from the start of standing estrous behavior to ovulation was $30 \pm 1.1$ $\mathrm{h}$ (range 23-43 h). The time from the start of an AC to ovulation, being more accurate, would be a more reliable indicator of ovulation ( $27 \pm 1 \mathrm{~h}$; range $21-39 \mathrm{~h}$ ) and, on average, the periovulatory FSH peak occurred at the time of ovulation. A reliable indicator of the time of ovulation would be the interval from the start of a cow's AC, Heatime could alert the farmer as to when the AC started (when the cows next enter the milking parlor). It can identify for the farmer the optimum time to AI, which is during a 12 - to 18 -h window before the predicted time of ovulation. This optimum time is, on average, between 9 and $15 \mathrm{~h}$ after the activity cluster has been triggered.

\section{ACKNOWLEDGMENTS}

This study was funded from a Science Foundation Ireland grant (07/SRC/B1156; Dublin, Ireland). The authors thank Progressive Genetics (Dublin, Ireland) for supplying the Heatime equipment. Special thanks go to the University College Dublin Reproductive Biology Research Cluster team for their help during the field work and to the staff at the Lyons Research Farm (Newcastle, Co. Dublin, Ireland) for their assistance. Special thanks go to the staff in the hormone assay and clinical pathology laboratories (University College Dublin Veterinary Sciences Centre) for their expert technical assistance.

\section{REFERENCES}

Aungier, S. P. M., J. F. Roche, M. Sheehy, and M. A. Crowe. 2012 Effects of management and health on the use of activity monitoring for estrus detection in dairy cows. J. Dairy Sci. 95:2452-2466.

Bernard, C., J. P. Valet, R. Beland, and R. D. Lambert. 1983. Prediction of bovine ovulation by a rapid radioimmunoassay for plasma LH. J. Reprod. Fertil. 68:425-430.

Bloch, A., Y. Folman, M. Kalm, Z. Roth, R. Braw-Tal, and D. Wolfenson. 2006. Endocrine alterations associated with extended time interval between estrus and ovulation in high-yield dairy cows. J. Dairy Sci. 89:4694-4702.

Caraty, A., B. Delaleu, D. Chesneau, and C. Fabre-Nys. 2002. Sequential role of $\mathrm{E} 2$ and $\mathrm{GnRH}$ for the expression of estrous behavior in ewes. Endocrinology 143:139-145.

Caraty, A., and D. C. Skinner. 2008. Gonadotropin-releasing hormone in third ventricular cerebrospinal fluid: Endogenous distribution and exogenous uptake. Endocrinology 149:5227-5234. 
Cooke, D. J., M. A. Crowe, and J. F. Roche. 1997. Circulating FSH isoform patterns during recurrent increases in FSH throughout the estrous cycle of heifers. J. Reprod. Fertil. 110:339-345.

Crowe, M. A., V. Padmanabhan, N. Hynes, S. J. Sunderland, W. J. Enright, I. Z. Beitins, and J. F. Roche. 1997. Validation of a sensitive radioimmunoassay to measure serum follicle-stimulating hormone in cattle: correlation with biological activity. Anim. Reprod. Sci. $48: 123-136$

D'Occhio, M. J., G. Sudha, D. Jillela, T. Whyte, L. J. Maclellan, J. Walsh, T. E. Trigg, and D. Miller. 1998. Close synchrony of ovulation in superstimulated heifers that have a down regulated anterior pituitary gland and are induced to ovulate with exogenous LH. Theriogenology 49:637-644.

Dalton, J. C. 2011. Strategies for success in heat detection and artificial insemination. Adv. Dairy Technol. 23:215-229.

Dieleman, S. J., M. M. Bevers, H. T. M. Van Tol, and A. H. Willemse. 1986. Peripheral plasma concentrations of oestradiol, progesterone, cortisol, LH, and prolactin during the oestrous cycle in the cow, with emphasis on the perioestrous period. Anim. Reprod. Sci. 10:275-292.

Diskin, M. G. 2008. Reproductive management of dairy cows: A review (part 1). Ir. Vet. J. 61:326-332.

Diskin, M. G., and J. M. Sreenan. 2000. Expression and detection of estrus in cattle. Reprod. Nutr. Dev. 40:481-491.

Dobson, H. 1978. Plasma gonadotrophins and oestradiol during oestrus in the cow. J. Reprod. Fertil. 52:51-53.

Dobson, H., R. F. Smith, M. D. Royal, C. H. Knight, and I. M. Sheldon. 2007. The high producing dairy cow and its reproductive performance. Reprod. Domest. Anim. 42(Suppl. 2):17-23.

Dobson, H., S. L. Walkera, M. J. Morris, J. E. Routly, and R. F. Smith. 2008. Why is it getting more difficult to successfully artificially inseminate dairy cows? Animal 2:1104-1111.

Dransfield, M. B. G., R. L. Nebel, R. E. Pearson, and L. D. Warnick. 1998. Timing of insemination for dairy cows identified in estrus by a radiotelemetric estrus detection system. J. Dairy Sci. $81: 1874-1882$

Duchens, M., G. Fredriksson, H. Kindahl, and S. Aiumlamai. 1993. Effect of intracervical administration of a prostaglandin E2 gel in pregnant and non-pregnant heifers. Vet. Rec. 133:546-549.

Edmonson, A. J., I. J. Lean, L. D. Weaver, T. Farver, and G. Webster. 1989. A body condition scoring chart for Holstein dairy cows. J. Dairy Sci. 72:68-78.

Fabre-Nys, C., and G. B. Martin. 1991. Hormonal control of proceptive and receptive sexual behaviour and the pre-ovulatory LH surge in the ewe: reassessment of the respective roles of estradiol, testosterone and progesterone. Horm. Behav. 25:295-312.

Forde, N., M. E. Beltman, G. B. Duffy, P. Duffy, J. P. Mehta, P. Ó Gaora, J. F. Roche, P. Lonergan, and M. A. Crowe. 2011. Changes in the endometrial transcriptome during the bovine estrous cycle: Effect of low circulating progesterone and consequences for conceptus elongation. Biol. Reprod. 84:266-278.

Friend, T. H., C. E. Polan, F. C. Gwazdauskas, and C. W. Heald. 1977. Adrenal glucocorticoid response to exogenous adrenocorticotropin mediated by density and social disruption in lactating cows. J. Dairy Sci. 60:1958-1963.

Gazal, O. S., L. S. Leshin, R. L. Stanko, M. G. Thomas, D. H. Keisler, L. L. Anderson, and G. L. Williams. 1998. Gonadotropin-releasing hormone secretion into third-ventricle cerebrospinal fluid of cattle: Correspondence with tonic and surge release of luteinizing hormone and its tonic inhibition by suckling and neuropeptide Y. Biol. Reprod. 59:676-683.

Gilmore, H. S., F. J. Young, D. C. Patterson, A. R. G. Wylie, R. A. Law, D. J. Kilpatrick, C. T. Elliott, and C. S. Mayne. 2011. An evaluation of the effect of altering nutrition and nutritional strategies in early lactation on reproductive performance and estrous behavior of high-yielding Holstein-Friesian dairy cows. J. Dairy Sci. 94:3510-3526.

Gümen, A., and M. C. Wiltbank. 2002. An alteration in the hypothalamic action of estradiol due to lack of progesterone exposure can cause follicular cysts in cattle. Biol. Reprod. 66:1689-1695.
Haughian, J. M., O. J. Ginther, K. Kot, and M. C. Wiltbank. 2004 Relationships between FSH patterns and follicular dynamics and the temporal associations among hormones in natural and $\mathrm{GnRH}-$ induced gonadotrophin surges in heifers. Reproduction 127:23-33.

Heres, L., S. J. Dieleman, and F. J. C. M. Van Eerdenberg. 2000. Validation of a new method of visual oestrus detection on the farm. Vet. Q. 22:50-55.

Holman, A., J. Thompson, J. E. Routly, J. Cameron, D. N. Jones, D. Grove-White, R. F. Smith, and H. Dobson. 2011. Comparison of estrus detection methods in dairy cattle. Vet. Rec. 169:47-53.

Hunter, R. H. F. 1994. Causes for failure of fertilization in domestic species. Pages 1-22 in Embryonic Mortality in Domestic Species. M. T. Zavy and R. D. Geisert, ed. CRC Press, Boca Raton, FL.

Hurnik, J. F., G. J. King, and H. A. Robertson. 1975. Estrous and related behaviour in postpartum Holstein cows. Appl. Anim. Ethol. 2:55-68.

Jennes, L., O. Eyigor, J. A. Janovick, and P. M. Conn. 1997. Brain gonadotropin releasing hormone receptors: Localization and regulation. Recent Prog. Horm. Res. 52:475-490.

Johnson, H. E., and J. J. Reeves. 1988. A luteinizing hormone-releasing hormone-induced serum luteinizing hormone surge is not detectable in the milk of cows. J. Anim. Sci. 66:442-446.

Kaneko, H., J. Noguchi, K. Kikuchi, J. Todoroki, and Y. Hasegawa. 2002. Alterations in peripheral concentrations of inhibin A in cattle studied using a time-resolved immunofluorometric assay: Relationship with estradiol and follicle-stimulating hormone in various reproductive conditions. Biol. Reprod. 67:38-45.

Karsch, F. J., and N. P. Evans. 1996. Feedback actions of estradiol on GnRH secretion during the follicular phase of the estrous cycle. Acta Neurobiol. Exp. (Warsz.) 56:715-725.

Lopez, H., T. D. Bunch, and M. P. Shipka. 2002. Estrogen concentrations in milk at estrus and ovulation in dairy cows. Anim. Reprod. Sci. $72: 37-46$

Lopez, H., L. D. Satter, and M. C. Wiltbank. 2004. Relationship between level of milk production and estrous behavior of lactating dairy cows. Anim. Reprod. Sci. 81:209-223.

Lyimo, Z. C., M. Nielen, W. Ouweltjes, T. A. M. Kruip, and F. J. C. M. Van Eerdenburg. 2000. Relationship among estradiol, cortisol and intensity of estrous behavior in dairy cattle. Theriogenology $53: 1783-1795$.

Martin, T. E., D. M. Henricks, J. R. J. Hill, and N. C. Rawlings. 1978 Active immunization of the cow against oestradiol-173. J. Reprod. Fertil. 53:173-178.

Mizrachi, D., and M. Shemesh. 1999. Expression of functional luteinizing hormone receptor and its messenger ribonucleic acid in bovine cervix: luteinising hormone augmentation of intracellular cAMP phosphate inositol and cyclooxygenase. Mol. Cell Endocrinol. 157:191-200

Mosher, M. D., J. S. Ottobre, G. K. Haibel, and D. L. Zartman. 1990 Estrual rise in body temperature in the bovine. 11. The temporal relationship with ovulation. Anim. Reprod. Sci. 23:99-108.

Nebel, R. L., S. M. Jobst, M. B. G. Dransfield, S. M. Pandolfi, and T. L. Bailey. 1997. Use of a radiofrequency data communication system, Heat Watch, to describe behavioral estrus in dairy cattle. J. Dairy Sci. 80(Suppl. 1):151. (Abstr.)

Pape-Zambito, D. A., R. F. Roberts, and R. S. Kensinger. 2010. Estrone and $17 \beta$-estradiol concentrations in pasteurized-homogenized milk and commercial dairy products. J. Dairy Sci. 93:2533-2540.

Peralta, O. A., R. E. Pearson, and R. L. Nebel. 2005. Comparison of three estrus detection systems during summer in a large commercial dairy herd. Anim. Reprod. Sci. 87:59-72.

Prendiville, D. J., W. J. Enright, M. A. Crowe, M. Finnerty, N. Hynes, and J. F. Roche. 1995. Immunization of heifers against gonadotropin-releasing hormone: Antibody titres, ovarian function, body growth and carcass characteristics. J. Anim. Sci. 73:2382-2389.

Rajamahendran, R., J. Robinson, S. Desbottes, and J. S. Walton. 1989. Temporal relationships among estrus, body temperature, milk yield, progesterone, and luteinizing hormone levels, and ovulation in dairy cows. Theriogenology 31:1173-1182. 
Rissman, E. F., S. R. Wersinger, J. A. Taylor, and D. B. Lubhan. 1997. Estrogen receptor function as revealed by knockout studies: neuroendocrine and behavioral aspects. Horm. Behav. 31:232-243.

Rizzo, A., D. Campanile, M. Mutinati, G. Minoia, M. Spedicato, and R. L. Sciorsci. 2011. Epidural vs intramuscular administration of Lecirelin, a GnRH analogue, for the resolution of follicular cysts in dairy cows. Anim. Reprod. Sci. 126:19-22.

Roelofs, J. B., E. G. Bouwman, S. J. Dieleman, F. J. C. M. Van Eerdenburg, L. M. Kaal-Lansbergen, N. M. Soede, and B. Kemp. 2004. Influence of repeated rectal ultrasound examinations on hormone profiles and behaviour around oestrus and ovulation in dairy cattle. Theriogenology 62:1337-1352.

Roelofs, J. B., E. A. M. Graat, E. Mullaart, N. M. Soede, W. Voskamp-Harkema, and B. Kemp. 2006. Effects of insemination-ovulation interval on fertilization rates and embryo characteristics in dairy cattle. Theriogenology 66:2173-2181.

Roelofs, J. B., F. J. C. M. Van Eerdenburg, N. M. Soede, and B. Kemp. 2005a. Various behavioral signs of estrous and their relationship with time of ovulation in dairy cattle. Theriogenology 63:1366-1377.

Roelofs, J. B., F. J. C. M. Van Eerdenburg, N. M. Soede, and B. Kemp. 2005b. Pedometer readings for estrous detection and as predictor for time of ovulation in dairy cattle. Theriogenology 64:1690-1703.

Sangsritavong, S., D. K. Combs, R. Sartori, and M. C. Wiltbank. 2002. High feed intake increases blood flow and metabolism of progesterone and estradiol-173 in dairy cattle. J. Dairy Sci. 85:2831-2842.

Saumande, J., and P. Humblot. 2005. The variability in the interval between estrus and ovulation in cattle and its determinants. Anim. Reprod. Sci. 85:171-182.

Schoenemann, H. M., W. D. Humphrey, M. E. Crowder, T. M. Nett, and J. J. Reeves. 1985. Pituitary luteinizing hormone-releasing hormone receptors in ovariectomized cows after challenge with ovarian steroids. Biol. Reprod. 32:574-583.

Schwartz, N. B., and J. R. McCormack. 1972. Reproduction: Gonadal function and its regulation. Annu. Rev. Physiol. 34:425-472.

Shemesh, M., D. Mizrachi, M. Gurevich, Y. Stram, L. S. Shore, and M. J. Fields. 2001. Functional importance of bovine myometrial and vascular LH receptors and cervical FSH receptors. Semin. Reprod. Med. 19:87-96.

Sprecher, D. J., D. E. Hostetler, and J. B. Kaneene. 1997. A lameness scoring system that uses posture and gait to predict dairy cattle reproductive performance. Theriogenology 47:1179-1187.
Stoebel, D. P., and G. P. Moberg. 1982. Effect of adrenocorticotropin and cortisol on luteinizing hormone surge and estrous behavior of cows. J. Dairy Sci. 65:1016-1024.

Sunderland, S. J., M. A. Crowe, M. P. Boland, J. F. Roche, and J. J. Ireland. 1994. Selection, dominance and atresia of follicles during the estrous cycle of heifers. J. Reprod. Fertil. 101:547-555.

Terasawa, E., and G. A. Davis. 1983. The LHRH neuronal system in female rats: Relation to the medial preoptic nucleus. Endocrinol Jpn. 30:405-417.

Trimberger, G. W. 1948. Breeding efficiency in dairy cattle from artificial insemination at various intervals before and after ovulation. Nebraska Agric. Exp. Stn. Res. Bull. 153:1-26.

Trimberger, G. W., and H. P. Davis. 1943. Conception rate in dairy cattle from artificial insemination at various stages of estrus. Nebraska Agric. Exp. Stn. Res. Bull. 129:1-14.

Van Eerdenburg, F. J. C. M., D. Karthaus, M. A. M. Taverne, I. Merics, and O. Szenci. 2002. The relationship between estrous behavioural score and time of ovulation in dairy cattle. J. Dairy Sci. $85: 1150-1156$

Van Eerdenburg, F. J. C. M. 2008. Possible causes for the diminished expression of estrus behaviour. Vet. Q. 30(Suppl. 1):79-100.

Van Eerdenburg, F. J. C. M., A. J. J. M. Daemen, E. M. Van der Beek, and F. W. Leewen. 2000. Changes in estrogen-receptor immunoreactivity during the estrus cycle in lactating dairy cattle. Brain Res. 880:219-223.

Van Eerdenburg, F. J. C. M., S. H. Loeffler, and J. H. Van Vliet. 1996. Detection of oestrus in dairy cows: A new approach to an old problem. Vet. Q. 18:52-54.

Walker, S. L., R. F. Smith, D. N. Jones, J. E. Routly, M. J. Morris, and H. Dobson. 2010. The effect of a chronic stressor, lameness, on detailed sexual behaviour and hormonal profiles in milk and plasma of dairy cattle. Reprod. Domest. Anim. 45:109-117.

Yahalom, D., A. Chen, N. Ben-Aroya, S. Rahimipour, E. Kaganovsky, E. Okon, M. Fridkin, and Y. Koch. 1999. The gonadotropin-releasing hormone family of neuropeptides in the brain of human, bovine, and rat: identification of a third isoform. FEBS Lett. 463:289-294.

Yoshioka, K., C. Suzuki, S. Aria, S. Iwamura, and H. Hirose. 2001. Gonadotropin-releasing hormone in third ventricular cerebrospinal fluid of the heifer during the estrous cycle. Biol. Reprod. 64:563-570. 